Göttinger Bibliotheksschriften 36 



\section{Ungarische Literatur in deutscher Sprache}

Bibliographie der Neuerscheinungen 2000-2005

Bearbeitet von Christine Schlosser

Göttingen

2006 
Christine Schlosser

Kochelseestr. 4

12527 Berlin

E-Mail: Ingschloss@aol.com

Tel.: $\quad+49(0) 306740260$

(C) Niedersächsische Staats- und Universitätsbibliothek Göttingen 2006 Herausgegeben von Elmar Mittler

ISBN $10: 3-930457-80-6$

ISBN 13 : 978-3-930457-80-9

ISSN 0943-951X 


\section{Inhalt}

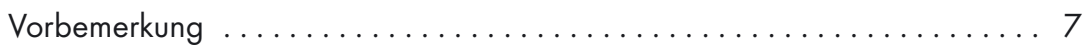

I. Belletristik .................................... 9

Ungarische Autoren ................................ 10

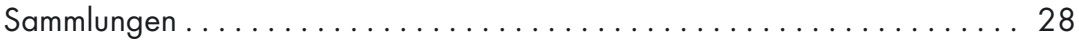

Autoren, die in deutscher bzw. in anderen Sprachen schreiben ........ 32

Ungarndeutsche Autoren ......................... 37

II. Sachliteratur . ................................ 39

Philosophie .............................. 40

Geschichte ................................. 41

Archäologie ................................ 55

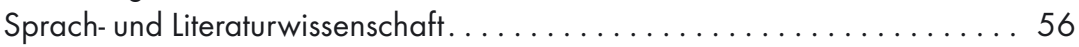

Theater, Film, Musik .............................. 66

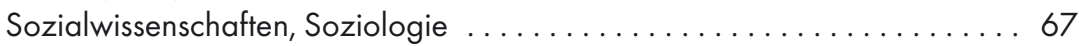

Ethnologie ..................................69 69

Psychologie.................................. 70

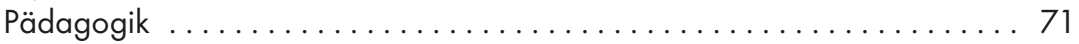

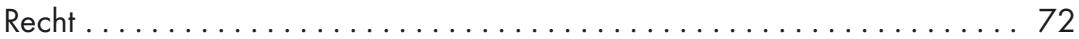

Politologie, Wirtschaft. ............................ 76

Zeitschriften.................................. 81

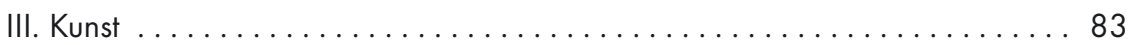

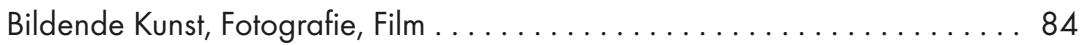

Architektur ................................ 89

Übersetzerregister (Belletristik) . . . . . . . . . . . . . . . . . 91 



\section{Vorbemerkung}

Die ungarische Literatur ist seit dem Beginn des 19. Jahrhunderts im deutschsprachigen Raum präsent, wobei ihre Wahrnehmung immer von Höhen und Tiefen begleitet war. Die Einzigartigkeit der ungarischen Sprache erwies sich in gewisser Weise als Barriere, einen Platz im Kreis der europäischen Literaturen zu erringen. György Konrád sieht aber darin auch eine positive Wirkung, wenn er davon spricht, dass die Isolierung der ungarischen Sprache die Literatur eingehüllt habe wie die Nussschale den Kern und ihr durch die Schaffung einer intensiven Innerlichkeit zugleich Schutz gewähre.

Seit etwa Mitte der neunziger Jahre feiern ungarische Autoren in deutschen und europäischen Literaturkreisen große Erfolge. Mit der Frankfurter Buchmesse 1999, auf der Ungarn den Schwerpunkt bildete, konnte die lange Zeit weitgehend unbekannte Literatur durch eine Vielzahl von Neuerscheinungen und Veranstaltungen die Aufmerksamkeit des deutschen Lesepublikums erlangen.

2002 erhielt Imre Kertész für sein literarisches Werk den Literatur-Nobelpreis. Die Werke von Imre Kertész, Péter Esterházy, György Konrád, Péter Nádas und György Dalos gehören mittlerweile zum fest etablierten Kanon innerhalb der deutschen Literaturszene und wurden mehrfach mit Preisen ausgezeichnet. Aber auch moderne junge Autoren wie z. B. László Darvasi, Attila Bartis und László Márton - gehören zum Programm der großen deutschen Verlage. Seit Mitte der neunziger Jahre erobern erfreulicherweise auch Schriftsteller der klassischen ungarischen Moderne wie Sándor Márai, Antal Szerb und Dezső Kosztolányi die deutschen Bestsellerlisten und lösten eine Art Boom der ungarischen Zwischenkriegsliteratur aus. László F. Földényi sieht das Erfolgsgeheimnis Márais und der anderen „zur Hälfte gewiss im internationalen Einschlag dieser Autoren - darin, dass sie an Fragen rühren, die ganz Europa vertraut waren, und dass sie diese Fragen auf vertraute Art servierten. (Neve Zürcher Zeitung, 6. November 2004).

Nicht zu vergessen bleibt, dass sich vor allem kleine Verlage um klassische Autoren wie z.B. Géza Csáth, Béla Balázs und Frigyes Karinthy, aber auch um junge ambitionierte Schriftsteller verdient gemacht haben.

Diese insgesamt erfreuliche Entwicklung möchte die vorliegende Bibliographie empirisch dokumentieren. Um die Vielfältigkeit des kulturellen und wissenschaftlichen Transfers zwischen Ungarn und Deutschland zu unterstreichen, wurden auch Bücher aus den Bereichen Sprach- und Literaturwissenschaft, Geschichte, Philosophie, Politik, Wirtschaft 
und Kunst, die Ungarn betreffende Themen zum Gegenstand haben, berücksichtigt. Für die Zusammenstellung der vorliegenden Bibliographie wurden das Verzeichnis lieferbarer Bücher (VLB), die Deutsche Nationalbiographie, die einschlägigen deutschen Bibliothekskataloge sowie der Katalog der Széchényi Nationalbibliothek Budapest für den Zeitraum 2000 bis 2005 ausgewertet.

Es bleibt zu hoffen, dass die vorliegende Dokumentation auf ein breites Interesse bei Verlagen, Rezensenten und vor allem bei den begeisterten Lesern stößt und die Neugier auf eine der vielfältigsten und aufregendsten Literaturlandschaften Europas weckt.

Dezember 2005

Christine Schlosser 
I. Belletristik 


\section{Ungarische Autoren}

Ady, Endre (1877-1919)

Ausgewählte Gedichte. Ungarisch-Deutsch. Neu übertragen mit Anmerkungen zum Textverständnis von Wolfgang Brunsch. Aachen: Shaker Verlag, 1999. - 138 S. (Berichte aus der Literaturwissenschaft) ISBN 3-8265-6325-5

Ungarische Lyrik 1877- 1919. Ausgewählte Gedichte. Übertragen aus dem Ungarischen von Julius Alexander Detrich. Herausgegeben von Gudrun Detrich. [Mit einem Vorwort von Wilhelm Droste]. Olching: G. Detrich; Norderstedt: Books on Demand GmbH, 2001. - 123 S. ISBN 3-8311-2250-4

Balázs, Béla (1884-1949)

Ein Baedeker der Seele und andere Feuilletons aus den Jahren 1920-1926. Herausgegeben von Hanno Loewy. Berlin: Das Arsenal, 2002. - 157 S. (Ausgewählte literarische Werke in Einzelausgaben; 2) ISBN 3-931109-30-5

Die Geschichte von der Logodygasse, vom Frühling, vom Tod und von der Ferne. Aus dem Ungarischen von Magdalena Ochsenfeld. Mit einem Nachwort von Julia Lenkei. Herausgegeben von Hanno Loewy. Berlin: Das Arsenal, 2003. - 132 S. (Ausgewählte literarische Werke in Einzelausgaben; 3) ISBN 3-931109-31-3

Der heilige Räuber und andere Märchen. Herausgegeben von Hanno Loewy. Berlin: Das Arsenal, 2004. (Ausgewählte literarische Werke in Einzelausgaben; 4) ISBN 3-931109$37-2$

Die Jugend eines Träumers. Autobiographischer Roman. Herausgegeben von Hanno Loewy. Berlin: Das Arsenal, 2001. - 375 S. (Ausgewählte literarische Werke in Einzelausgaben; 1) ISBN 3-931109-19-4

\section{Balla, Zsófia (1949)}

Schwerkraft und Mitte. Gedichte. Aus dem Ungarischen und mit einem Nachwort von Daniel Muth. Berlin: DAAD Berliner Künstlerprogramm, 2001. - 96 S. (Spurensicherung; 6) ISBN 3-89357-098-5

\section{Bari, Árpád (1953)}

... hier musst du leben und sterben ... Die Ungarn - das unbekannte Nachbarvolk. Ein subjektives Lesebuch für jeden, der in den Zeiten der Globalisierung mit einem (oder mehreren) Ungarn zu tun hat. Frankfurt a. M.: Rita G. Fischer, 2003. - 117 S. (Edition Fischer) ISBN 3-8301-0569-X 
KulturSchock Ungarn. Bielefeld: Reise-Know-How-Verlag Rump, 2005. - 208 S. ISBN 38317-1383-9

\section{Bartis, Attila (1968)}

Die Ruhe. Roman. Aus dem Ungarischen von Agnes Relle. Frankfurt a. M.: Suhrkamp, 2005. - 300 S. ISBN 3-518-41682-0 EST: A nyugalom

\section{Bitó, László (1934)}

Abraham und Isaak. Roman nach der Bibel. Aus dem Ungarischen von Paul Kárpáti. Bearbeitet von Kerstin Engelbrecht. Herne: Gabriele Schäfer Verlag, 2000. - 305 S. ISBN 3933337-21-6 EST: Ábrahám és Izsák

\section{Bozai, Ágota (1965)}

Irren ist göttlich. Roman. Aus dem Ungarischen von Christina Kunze. Wien: Kremayr \& Scheriau, 2001. - 282 S. ISBN 3-218-0086-4 EST: Tranzít glória

dass. [1. genehmigte Taschenbuchausgabe]. [München]: Goldmann, 2003. 282 S. (btb; 72612) ISBN 3-442-72612-3

\section{Dalos, György (1943)}

Der Gottsucher. Eine Geschichte. Aus dem Ungarischen übertragen von György Dalos und Elsbeth Zylla. Frankfurt a. M.: Suhrkamp, 2001. - 171 S. (stb; 3251) ISBN 3-51839751 EST: Istenkereső

Die Reise nach Sachalin. Auf den Spuren von Anton Tschechow. Deutsche Bearbeitung von Elsbeth Zylla. Fotos, Text- und Materialrecherchen von Andrea Dunai. Hamburg: Europäische Verlags-Anstalt, 2001. - 285 S. ISBN 3-434-50503-2

Seilschaften. Aus dem Ungarischen von György Dalos und Elsbeth Zylla. Köln: Dumont Literatur und Kunst Verlag, 2002. - 359 S. ISBN 3-8321-6004-3 EST: Cohen úr ismerősei

\section{Darvasi, László (1962)}

Die Hundejäger von Lojang. Chinesische Geschichten. Aus dem Ungarischen von Heinrich Eisterer. Frankfurt a. M.: Suhrkamp, 2003. - 164 S. ISBN 3-518-41427-5 EST: A Lojangi kutyavadászok. Kínai novellák

Eine Frau besorgen. Kriegsgeschichten. Aus dem Ungarischen von Heinrich Eisterer, Terézia Mora und Agnes Relle. Frankfurt a. M.: Suhrkamp, 2003. - 181 S. (es; 2448) ISBN 3518-12448-X EST: Szerezni egy nót 
Die Legende von den Tränengauklern. Roman. Aus dem Ungarischen von Heinrich Eisterer. Frankfurt a. M.: Suhrkamp Verlag, 2001. - 576 S. ISBN 3-518-41284-1 EST: A könnymutatványosok legendája

Déry, Tibor (1894-1977)

Niki oder die Geschichte eines Hundes. Erzählung. Aus dem Ungarischen übersetzt und mit einem Nachwort von Ivan Nagel. Berlin: Das Arsenal, 2001. - 109 S. ISBN 3-93110926-7 EST: Niki, egy kutya története

\section{Domokos, Johanna (1970)}

Bordó erdő - Read forest - Roter Wald. Astrid Preston (Bilder). Michael Heim (Englische Übersetzung). Christine Schlosser (Deutsche Übersetzung). Cluj: Apokrif, 2004. - 47 S. ISBN 952979 64-4-4

Napút. VersTérkép. Sonnenreise. GedichtLandkarte. Aus dem Ungarischen von Irene Rübberdt. Marosvásárhely: Mentor, 2001. - o. P. ISBN 973-8002-90-7

Eörsi, István (1931 - 2005)

Am Morgen meines Todes. Schauspiel. Aus dem Ungarischen von Gregor Mayer. Den Bühnen und Vereinen gegenüber als Manuskript gedruckt. Frankfurt a. M.: Verlag der Autoren, 2001. - $57 \mathrm{~S}$.

Ich fing eine Fliege beim Minister. Prosa. Aus dem Ungarischen von Zsuzsanna Gahse. Veränderte Neuauflage. Klagenfurt; Salzburg: Wieser Verlag, 2004. - 169 S. (Wortlandstreicher) ISBN 3-85129-457-2

Der rätselhafte Charme der Freiheit. Versuche über das Neinsagen. Aus dem Ungarischen von Anna Gara-Bak, Péter Máté, Gregor Mayer, Angela Plöger und Hans Skirecki. Frankfurt a. M.: Suhrkamp, 2003. - 197 S. (es; 2271) ISBN 3-518-12271-1

\section{Esterházy, Péter (1950)}

Das Buch Hrabals. Roman. Neu durchgesehene Fassung. Aus dem Ungarischen von Zsuzsanna Gahse. Berlin: Berliner Taschenbuch Verlag, 2004. - 208 S. (BvT; 32) ISBN 38333-0032-9 EST: Hrabal könyve

Fancsikó und Pinta. Geschichten auf ein Stück Schnur gefädelt. Aus dem Ungarischen von Zsuzsanna Gahse. Berlin: Berlin Verlag, 2002. - 143 S. ISBN 3-8270-0406-3 EST: Fancsikó és Pinta

dass. Aus dem Ungarischen von Zsuzsanna Gahse. Berlin: Berliner Taschenbuch Verlag, 2004. - 136 S. (BvT; 89) ISBN 3-8333-0089-2 
dass. Gelesen von Walter Kreye. Aus dem Ungarischen von Zsuzsanna Gahse. Hamburg: HörbuchHamburg, 2004. - Audio-CD. ISBN 3-89903-174-1

Eine Frau. Aus dem Ungarischen von Zsuzsanna Gahse. Berlin: Berliner Taschenbuchverlag, 2002. - 207 S. (BvT; 76123) ISBN 3-442-76123-9 EST: Egy nó

dass. Gelesen von Ulrich Pleitgen. Aus dem Ungarischen von Zsuzsanna Gahse. Hamburg: HörbuchHamburg, 2004. - Audio-CD. ISBN 3-89903-173-3

Harmonia Caelestis. Aus dem Ungarischen von Terézia Mora. Berlin: Berlin Verlag, 2001. - 920 S. ISBN 3-8270-0405-5 EST: Harmonia caelestis

dass. Berlin: Berliner Taschenbuch Verlag, 2003. - 920 S. (BvT; 76161) ISBN 3442-76161-1

dass. Frankfurt a. M.; Wien; Zürich: Büchergilde Gutenberg, 2002. - 920 S. ISBN 3-7632-5256-8

Harmonia caelestis/Verbesserte Ausgabe/ Marginalien. Kassette in drei Bänden. Zwei Romane, ein Marginalienband. Berlin: Berlin Verlag, 2003. - ca. 1304 S. ISBN 3-82700510-8

Die Hilfsverben des Herzens. Roman. Aus dem Ungarischen von Hans-Henning Paetzke. Mit einem Nachwort von Imre Kertész. Frankfurt a. M.: Suhrkamp, 2004. - 131 S. (Bibliothek Suhrkamp; 1374) ISBN 3-518-22374-7 EST: A szív segédígei

Verbesserte Ausgabe. Aus dem Ungarischen von Hans Skirecki. Berlin: Berlin Verlag, 2003. - 364 S. ISBN 3-3870-0497-7 EST: Javított kiadás

dass. 2. Auflage. Berlin: Berliner Taschenbuch-Verlag, [2005]. - 371 S. (BvT; 135) ISBN 3-8333-0135-X

Was für ein Péter! Über Péter Esterházy. Herausgegeben von Angelika Klammer. Berlin: Berliner Taschenbuch-Verlag, 2005. - 175 S. (BvT; 205) ISBN 3-8333-0205-4

in: Steinfeld, Thomas (Hrsg.): „Einmal und nicht mehr”. Schriftsteller über das Alter. Stuttgart; München: Deutsche Verlags-Anstalt, 2001. - 141 S. ISBN 3-421-05449-5

dass. [Ungekürzte Ausgabe]. München: Deutscher Taschenbuch Verlag, 2002. 135 S. (dtv Belletristik; 13030) ISBN 3-423-13030-X 
Imre Kertész und Péter Esterházy lesen Eine Geschichte. Zwei Geschichten. Lesung rbb, Rundfunk Berlin-Brandenburg. [Berlin]: Der Audio Verlag, 2003. - 2 CDs. ISBN 3-89813$251-X$

Földényi, László F. (1952)

Mit dem Unbegreiflichen leben. Notizen aus Berlin. Essays. Aus dem Ungarischen von Hans Skirecki und Ákos Doma. Berlin: DAAD Berliner Künstlerprogramm, 2000. - 59 S. (Spurensicherung; 2) ISBN 3-89357-090-X

Garaczi, László (1956)

Picasso sieht rot. Erzählungen. Aus dem Ungarischen von Andrea Seidler und Pál Deréky. Graz: Literaturverlag Droschl, 2002. - 111 S. ISBN 3-85420-599-6

Gárdonyi, Géza (1863-1922)

Die Gefangenen Gottes. [Aus dem Ungarischen von Terézia Jeszenkovits]. [Budapest]: Corvina, 2001. - 411 S. ISBN 963-13-4996-9 EST: Isten rabjai

Ich war den Hunnen untertan. [Aus dem Ungarischen übertragen von Heinrich Weissling]. [Budapest]: Corvina, ${ }^{9}$ 2000. - 300 S. ISBN 963-13-4911-X EST: A láthatatlan ember

\section{Gergely, Ágnes (1933)}

Die Unbehüteten. Roman. Aus dem Ungarischen von Hans Skirecki. Berlin: Aufbau-Verlag, 2002. - 192 S. ISBN 3-351-02945-4 EST: Örizetlenek

dass. Berlin: Aufbau-Taschenbuch-Verlag, 2003. - 192 S. (Aufbau-Tb; 1522) ISBN 3-7466-1522-4

\section{Görgey, Gábor (1929)}

Sirene der Adria. Autorisierte Übersetzung aus dem Ungarischen von Jörg Buschmann. Mit einem Vorwort von Imre Kertész. München: Salon LiteraturVerlag, 2004. - 238 S. ISBN 3-9809635-0-0 EST: Adria szirénje

\section{Györffy, László (1940)}

Schatten. Historischer Roman. Übertragen aus dem Ungarischen von Maria Jahn Brandenstein. Schweinfurt: Wiesenburg Verlag, 2003. - 242 S. ISBN 3-932497-95-3 EST: Aki megszökött a halál elött

Hamvas, Béla (1897-1968)

Bäume. Aus dem Ungarischen von Wilhelm Droste. Szentendre: Edition M, 2002. - 57 S. ISBN 963-85878-4-9 EST: Fák 
Harsányi, Zsolt (1887-1943)

Und sie bewegt sich doch. Der Galilei-Lebensroman. Roman. [Aus dem Ungarischen übersetzt und bearbeitet von J. P. Toth und A. Luther.] Genehmigte Sonderausgabe. [Augsburg]: Weltbild, [2004]. - 721 S. EST: És mégis mozog a föld

Heltai, Jenö (1871 - 1957)

Jaguar. [Übersetzt von Georg Harmat]. [Budapest]: Corvina, 2003. - 174 S. ISBN 963 13-5291-9 EST: Jaguár

Horváth, Ottó (1967)

Kanada. Gedichte. Übertragen von Martin Langanke. [Nachwort von Pia Erdmann und Martin Langanke]. Fürth: Verlag Martin Bernhard, 2000. - 37 S. (Laufschrift Edition) ISBN 3-932868-04-8

Howard, P. [d. i. Jenő Rejtő] (1905- 1943)

Ein Seemann von Welt. Roman. Aus dem Ungarischen übersetzł von Anna von Lindt. Nachwort von György Dalos. Berlin: Elfenbein Verlag, 2004. - 250 S. ISBN 3-932245-64-4 EST: Piszkos Fred, a kapitány

Illyés, Gyula (1902-1983)

Stiller Nachmittag. Gedichte in Prosa. Aus dem Ungarischen von Paul Kárpáti. Flein bei Heilbronn: Verlag Werner Schweikert, 2003. - 111 S. ISBN 3-933696-05-4

Jókai, Mór (1825 - 1904)

Ein Goldmensch. [Die Übersetzung von K. M. Kertbeny wurde bearbeitet von Henriette Schade-Engl]. [Budapest]: Corvina, ${ }^{5} 2001$. - 594 S. ISBN 963-13-4965-9 EST: Az aranyember

József, Attila (1905-1937)

Ein wilder Apfelbaum. Ungarisch und deutsch. Aus dem Ungarischen von Daniel Muth. Mit einem Vorwort von Ferenc Fejtő und einem Essay von György Dalos. Zürich: Ammann Verlag, 2005. ISBN 3-250-10488-4

\section{Kalász, Márton (1934)}

Dunkle Wunde. Hölderlin-Gedichte. Aus dem Ungarischen übersetzt von Julia und Robert Schiff. Heidelberg: Verlag Das Wunderhorn, 2002. - 48 S. (Edition Künstlerhaus) ISBN 388423-198-7

Dezimierungszettel. Aus dem Ungarischen von Robert und Julia Schiff. Budapest: VudAK, 2002. - 261 S. (Neve-Zeitung-Bücher; 3) ISBN 963-8333-06-5 
Der Rosenmaler. Gedichte. Aus dem Ungarischen von Franz Fühmann und Paul Kárpáti. Berlin:Verlag der Nessing'schen Buchdruckerei, 2004. - [35] S. (Die Nessing'schen Hefte; 3)

Kányádi, Sándor (1929)

Das weitgereiste Mäuschen. [Aus dem Ungarischen von Paul Kárpáti. Mit Zeichnungen von Emma Heinzelmann.] Budapest: Holnap Verlag, 2004. - 111 S. ISBN 963-346-630-X

\section{Kertész, Imre (1929)}

Detektivgeschichte. Aus dem Ungarischen von Angelika und Peter Máté. Reinbek bei Hamburg: Rowohlt, 2004. - 137 S. ISBN 3-498-03525-8 EST: Detektivtörténet

dass. 2. Auflage. Reinbek bei Hamburg: Rowohlt, 2005. - 137 S. ISBN 3-49803525-8

dass. [Tonträger]. Lesung. Sprecher Ulrich Noethen. Berlin: Der Audio Verlag, 2005. - 4 Teile. ISBN 3-89813-451-2

Die englische Flagge. Aus dem Ungarischen von Kristin Schwamm. Reinbek bei Hamburg: Rowohlt, ${ }^{2} 2002$. - 93 S. ISBN 3-498-0358-5 EST: Az angol lobogó

Die exilierte Sprache. Essays und Reden. Mit einem Vorwort von Péter Nádas. Aus dem Ungarischen von Kristin Schwamm, György Buda, Géza Deréky, Krisztina Koenen, László Kornitzer, Christian Polzin, Ilma Rakusa, Irene Rübberdt, Christina Viragh und Ernö Zeltner. Frankfurt a. M.: Suhrkamp, 2003. - 258 S. ISBN 3-518-41449-6

dass. Frankfurt a. M.: Suhrkamp, 2004. - 266 S. (Suhrkamp-Tb; 3655)

Fiasko. Roman. Aus dem Ungarischen von György Buda und Agnes Relle. Reinbek bei Hamburg: Rowohlt Taschenbuch Verlag, 2001. - 442 S. (rororo; 22909) ISBN 3-49922909-9 EST: A kudarc

Der Fremde. Du. Zeitschrift für Kultur. 757, Nr. 5, Juni 2005. ISBN 3-03717-015-8

"Heureka!". Rede zum Nobelpreis für Literatur 2002. Aus dem Ungarischen von Kristin Schwamm. Bearbeitung Ingrid Krüger. Frankfurt a. M.: Suhrkamp, 2002. - 30 S. (Sonderdruck edition suhrkamp) ISBN 3-518-06702-8

Ich - ein anderer. [Tonträger]. Gelesen von Dieter Mann. [Vollständige Lesung]. München: Der Hörverlag, 2003. - 3 CDs ISBN 3-89940-118-2 EST: Valaki más 
Kaddisch für ein nicht geborenes Kind. Roman. Aus dem Ungarischen von György Buda und Kristin Schwamm. München: Saur, 2003. (Grossdruck) ISBN 3-598-80061-4 EST: Kaddis a meg nem született gyermekért

Liquidation. Aus dem Ungarischen von Laszlo Kornitzer und Ingrid Krüger. Frankfurt a. M.: Suhrkamp, 2003. - 141 S. ISBN 3-518-41493-3 EST: Felszámolás

dass. [Tonträger]. Lesung. Produktion Hessischer Rundfunk 2004. Mit Dieter Mann. [Berlin]: Der Audio Verlag, 2004. - 4 CDs. ISBN 3-89813-297-8

dass. Reinbek bei Hamburg: Rowohlt Taschenbuch Verlag, 2005. - 141 S. (rororo; 24156) ISBN 3-499-24156-7

Protokoll. Erzählung. Übersetzung von Kristin Schwamm. Illustriert von Paul Löb. Passau: Thomas Reche, 2004. - 44 S. (Edition Refugium; 1) ISBN 3-929566-43-5 EST: Jegyzókönyv

Roman eines Schicksallosen. Aus dem Ungarischen von Christina Viragh. [Ungekürzte Ausgabe]. Reinbek bei Hamburg: Rowohlt Taschenbuch Verlag, 2004. - 412 S. (rororo Grossdruck; 33205) ISBN 3-499-33205-1 EST: Sorstalanság

dass. [Einmalige Sonderausgabe]. Reinbek: Rowohlt Taschenbuch Verlag, 2004. - 286 S. (rororo; 23590) ISBN 3-499-23590-0

dass. 19. Auflage. Reinbek bei Hamburg: Rowohlt Taschenbuch Verlag, 2005. 286 S. (rororo; 22576) ISBN 3-499-22576-X

dass. Mit Texten zum Film von Imre Kertész und Michael Töteberger. Reinbek bei Hamburg: Rowohlt Taschenbuch Verlag, 2005. - 288 S. (rororo; 24043) ISBN 3499-24043-2

dass. [Tonträger]. Gelesen von Imre Kertész und Ulrich Matthes. [Autorisierte Lesefassung]. München: Der Hörverlag, 1999. - 3 Tonkassetten. ISBN 3-89584-814-X

Schritt für Schritt. Drehbuch zum ,Roman eines Schicksallosen'. Aus dem Ungarischen von Erich Berger. Frankfurt a. M.: Suhrkamp, 2002. - 184 S. (es; 2292) ISBN 3-518-12292-4

Der Spurensucher. Erzählung. Aus dem Ungarischen übersetzt von György Buda. Mit einem Nachwort des Autors. Frankfurt a. M.: Suhrkamp, 2002. - 129 S. (Bibliothek Suhrkamp; 1357) ISBN 3-518-22357-7 EST: A nyomkereső 
dass. [Tonträger]. Gelesen von Walter Kreye. [Ungekürzte Lesung]. Hamburg: Hörbuch Hamburg, 2003. - 3 CDs. ISBN 3-89903-27-X

Imre Kertész und Péter Esterházy lesen Eine Geschichte. Zwei Geschichten. Lesung rbb, Rundfunk Berlin-Brandenburg. [Berlin]: Der Audio Verlag, 2003. - 2 CDs. ISBN 3-89813$251-X$

\section{Konrád, György (1933)}

Der dritte Blick. Betrachtungen eines Antipolitischen. Aus dem Ungarischen von HansHenning Paetzke. Frankfurt a. M.: Suhrkamp Verlag, 2001. - 217 S. (es; 2233) ISBN 3518-12233-5

Glück. Roman. Aus dem Ungarischen von Hans-Henning Paetzke. Frankfurt a. M.: Suhrkamp Verlag, 2003. - 155 S. ISBN 3-518-41445-3 EST: Elutazás és hazatérés

dass. Frankfurt a. M.: Suhrkamp Verlag, 2005. - 160 S. (st; 3662) ISBN 3-51845662-8

Sonnenfinsternis auf dem Berg. Autobiographischer Roman. Aus dem Ungarischen von Hans-Henning Paetzke. Frankfurt a. M.: Suhrkamp Verlag, 2005. - 381 S. ISBN 3-51841684-7 EST: Fenn a hegyen napfogyatkozáskor

Ungarn in Europa. Karlspreis 2001 an György Konrád. Herausgegeben von Armin Laschet und Friedbert Pflüger. Aachen: Einhard-Verlag, 2001. - 173 S. ISBN 3-930701-89-8

\section{Korbuly, Dezső (1932)}

Verkläre mein Bild. Auf den Spuren einer Kindheit. Egelsbach: Fouqué Literaturverlag, 2001. - 304 S. (Bibliothek der Zeitzeugen) ISBN 3-8267-4946-4

\section{Kosztolányi, Dezsö (1885-1936)}

Ein Held seiner Zeit. Die Bekenntnisse des Kornél Esti. Roman. Deutsch von Christina Viragh. Mit einem Nachwort von Péter Esterházy. Berlin: Rowohlt Berlin, 2004. - 302 S. ISBN 387134-489-3 EST: Esti Kornél

dass. Reinbek bei Hamburg: Rowohlt Taschenbuch Verlag, 2005. - 304 S. ISBN 3-499-24111-0

dass. [Tonträger]. Sprecher: Heikko Deutschmann. Hamburg: HörbucHHamburg, 2005. - 3 Teile. ISBN 3-89903-182-2 


\section{Krasznahorkai, László (1954)}

Im Norden ein Berg, im Süden ein See, im Westen Wege, im Osten ein Fluss. Roman. Aus dem Ungarischen von Christina Viragh. Zürich: Ammann Verlag, 2005. - 154 S. (Meridiane; 80) ISBN 3-250-60080-6 EST: Északról hegy, Délröl tó, Nyugatról utak, Keletról folyó

Krúdy, Gyula (1878-1933)

Schlemmergeschichten. Erzählungen. Aus dem Ungarischen von Hans Skirecki. Berlin; St. Petersburg: Oberbaum, 2002. - 193 S. ISBN 3-933314-37-2

Serenade vom durchstochenen Herzen. Sindbad-Novellen. Ausgewählt und ins Deutsche übertragen von Hans Skirecki. Berlin; St. Petersburg: Oberbaum, 2002. - 211 S. ISBN 3933314-17-8

Traumbuch. Aus dem Ungarischen von Hans Skirecki. Berlin; St. Petersburg: Oberbaum, 2002. - 355 S. ISBN 3-933314-49-6 EST: Álmoskönyv

\section{Lakatos, Menyhért (1926)}

Märchen der langen Nächte. Roma-Märchen. Aus dem Ungarischen von György Buda. Veränderte Neuauflage. Klagenfurt; Wien; Ljubliana; Sarajevo: Wieser Verlag, [2004]. 266 S. (Wortlandstreicher) ISBN 3-85129-453-X

\section{Mándy, Iván (1918 - 1995)}

Einsam und verloren. Zwei phantastische Erzählungen aus der Budapester Welt kleiner Leute. Aus dem Ungarischen von Hans-Henning Paetzke. Herne: Gabriele Schäfer Verlag, 2003. - 132 S. ISBN 3-933337-313

\section{Márai, Sándor (1900-1989)}

Bekenntnisse eines Bürgers. Aus dem Ungarischen von Hans Skirecki. Herausgegeben von Siegfried Heinrichs. München, Zürich: Piper, ${ }^{4} 2001$. - 419 S. ISBN 3-492-23081-4 EST: Egy polgár vallomásai

Die Fremde. Roman. Aus dem Ungarischen von Heinrich Eisterer. München: Piper, 2005. - 201 S. ISBN 3-492-04775-0 EST: A sziget

dass. [Tonträger]. Ungekürzte Lesung. Gelesen von Charles Braver. Hamburg: HörbucHHamburg, 2005. - 5 CDs. ISBN 3-89903-223-3

Die Glut. Roman. Aus dem Ungarischen und mit einem Nachwort von Christina Viragh. Ungekürzte Taschenbuchausgabe. München; Zürich: Piper, "2005. - 223 S. (Serie Piper; 3313) ISBN 3-492-23313-9 EST: A gyertyák csonkig égnek 
dass. Taschenbuchsonderausgabe. München; Zürich: Piper, 2002. - 223 S. (Serie Piper; 3587) ISBN 3-492-23587-5

dass. [Tonträger]. Hörspiel von Sebastian Goy. Sprecher: Thomas Holtzmann u.a. Hamburg: Hörbuch Hamburg, 2000. - 2 CDs ISBN 3-934120-61-X

dass. [Tonträger]. Christian Brückner liest Sándor Márai, Die Glut. Eine Aufnahme des Saarländischen Rundfunks. [Ungekürzte Fassung]. [Berlin]: Parlando, 2000. 5 Tonkassetten. ISBN 3-935125-01-1

Die Gräfin von Parma. Roman. Aus dem Ungarischen von Reneé von Stipsicz-Gariboldi. München; Zürich: Piper. 2002. - 239 S. (Piper Original; 7050) ISBN 3-492-27050-6 EST: Vendégiáték Bolzánóban

dass. München: Piper, 2004. - 256 S. (Serie Piper; 4040) ISBN 3-492-24040-2

dass. [Tonträger]. Hörspiel. Mit Rufus Beck, Lena Stolze u.v.a. [Berlin]: Der AudioVerlag, 2005. - 1 CD. ISBN 3-89813-394-X

Himmel und Erde. Betrachtungen. Aus dem Ungarischen übersetzt, mit Anmerkungen und einem Nachwort versehen von Ernö Zeltner. München, Zürich: Piper, 2001. - 341 S. ISBN 3-492-04284-8 EST: Ég és föld

dass. Aus dem Ungarischen übersetzt, mit Anmerkungen und einem Nachwort versehen von Ernö Zeltner. [Ungekürzte Taschenbuchausgabe]. München; Zürich: Piper, 2002. - 340 S. (Serie Piper; 3714) ISBN 3-492-23714-2

dass. [Tonträger]. Gelesen von Charles Braver. Hamburg: Hörbuch-Hamburg-Verlag Osterwold, 2001. - 1 CD. ISBN 3-934120-78-4

Ein Hund mit Charakter. Roman. Aus dem Ungarischen und mit einem Nachwort von Ernö Zeltner. München, Zürich: Piper, 2001. - 248 S. (Serie Piper; 7028: Piper Original) ISBN 3-492-27028-X EST: Csutora

dass. [Ungekürzte Taschenbuchausgabe]. München: Piper, ${ }^{3} 2005$. - 248 S. (Serie Piper; 4009) ISBN 3-492-24009-7

dass. [Tonträger]. Gelesen von Charles Braver. [Ungekürzte Lesung]. Hamburg: Hörbuch Hamburg, 2001. - 5 CDs. ISBN 3-89903-019-2 
Die jungen Rebellen. Roman. Aus dem Ungarischen von Ernö Zeltner. München, Zürich: Piper, 2001. - 277 S. ISBN 3-492-0428-4 EST: A zendülök

dass. [Ungekürzte Taschenbuchausgabe]. München: Piper, 2003. - 277 S. (Serie Piper; 3898) ISBN 3-492-23898-X

dass. [Tonträger]. Gelesen von Gustav-Peter Wöhler. [Ungekürzte Lesung]. Hamburg: Hörbuch Hamburg, 2001. - 6 CDs. ISBN 3-89903-017-6

Land, Land. Erinnerungen. Aus dem Ungarischen von Hans Skirecki. Herausgegeben von Siegfried Heinrichs. Ungekürzte Taschenbuchausgabe. München, Zürich: Piper, 2001. 317 S. (Serie Piper; 3184) ISBN 3-492-23184-5 EST: Föld, Föld!

Lieber Tibor. Briefwechsel Sándor Márai/ Tibor Simányi. Herausgegeben und aus dem Ungarischen übersetzt von Tibor Simányi. München; Zürich: Piper, 2002. - 335 S. ISBN 3-492-04377-1

Die Nacht vor der Scheidung. Aus dem Ungarischen von Margit Ban. München: Piper, 2004. - 219 S. ISBN 3-492-04287-2 EST: Válás Budán

dass. München: Piper, 2005. - 219 S. (Serie Piper; 4544) ISBN 3-492-24544-7

dass. [Die vorliegende Übersetzung wurde überarbeitet von Hanna Sieht]. Frankfurt a. M.; Wien; Zürich: Büchergilde Gutenberg, [2005]. - 219 S. ISBN 3-76325549-4

Ohne Anfang und Ende. Betrachtungen. Ausgewählt und aus dem Ungarischen übersetz† von Ernö Zeltner. [Teilausgabe]. München; Zürich: Piper, 2000. - 46 S. ISBN 3-49204271-6 EST: Ég és föld

Tagebücher und Briefe.

Bd. 1 Tagebücher. Auszüge, Fotos, Briefe und Dokumentationen. Aus dem Ungarischen von Hans Skirecki. Herausgegeben von Siegfried Heinrichs. Berlin; St. Petersburg: Oberbaum Verlag, 2001. - 162 S. ISBN 3-928254-94-4

Bd. 2 Tagebücher 1984-1989. Ausgewählt und aus dem Ungarischen übersetzł von Hans Skirecki. Herausgegeben von Siegfried Heinrichs. Berlin; St. Petersburg: Oberbaum Verlag, 2001. - 151 S. ISBN 3-933314-18-6 EST: Napló 1984-1989

Bd. 3 Tagebücher 1976-1983. Ausgewählt und aus dem Ungarischen übersetzt von Hans Skirecki. Herausgegeben von Siegfried Heinrichs. Berlin; St. Petersburg: Oberbaum Verlag, 2001. - 198 S. ISBN 3-933314-19-4 EST: Napló 1976-1983 
Bd. 4 Tagebücher 1968-1975. Ausgewählt und aus dem Ungarischen übersetzł von Hans Skirecki. Herausgegeben von Siegfried Heinrichs. Berlin; St. Petersburg: Oberbaum Verlag, 2001. - 304 S. ISBN 3-933314-20-8 EST: Napló 1968-1975

Bd. 5 Tagebücher 1958-1967. Ausgewählt und aus dem Ungarischen übersetzt von Hans Skirecki. Herausgegeben von Siegfried Heinrichs. Berlin; St. Petersburg: Oberbaum Verlag, 2001. - 311 S. ISBN 3-933314-21-6 EST: Napló 1968-1967

Bd. 6 Tagebücher 1945-1957. Ausgewählt und aus dem Ungarischen übersetzt von Paul Kárpáti. Herausgegeben von Siegfried Heinrichs. Berlin; St. Petersburg: Oberbaum Verlag, 2001. - 259 S. ISBN 3-933314-22-4 EST: Napló 1945-1957

Bd. 7 Tagebücher 1943-1944. Ausgewählt und aus dem Ungarischen übersetzł von Christian Polzin. Herausgegeben von Siegfried Heinrichs. Berlin; St. Petersburg: Oberbaum Verlag, 2001. - 262 S. ISBN 3-9333114-42-9 EST: Napló 19431944

Tagebücher 1984-1989. Ausgewählt und aus dem Ungarischen übersetzł von Hans Skirecki. Herausgegeben von Siegfried Heinrichs. Nachwort zur Taschenbuchausgabe von Ernö Zeltner. München; Zürich: Piper, 2002. - 154 S. (Serie Piper; 3183) ISBN 3492-23183-7 EST: Napló 1984- 1989

dass. [Tonträger]. Christian Brückner liest Sándor Márai, Tagebücher, 1985- 1989. Eine Auswahl. Übersetzt von Hans Skirecki. [Berlin]: Parlando, 2000. - 1 CD. (Edition Christian Brückner) ISBN 3-935125-02-X

Das Vermächtnis der Eszter. Roman. Aus dem Ungarischen von Christina Viragh. München, Zürich: Piper Verlag, 2000. - 164 S. ISBN 3-492-04198-1 EST: Eszter hagyatéka

dass. Frankfurt a. M.; Wien; Zürich: Büchergilde Gutenberg, 2001. - 164 S. ISBN 3-7632-5118-9

dass. [Ungekürzte Taschenbuchausgabe]. München; Zürich: Piper, 2002. - 164 S. (Serie Piper; 3511) ISBN 3-492-23511-5

dass. [Sonderausgabe].München: Piper, 2003. - 165 S. ISBN 3-492-04557-X

dass. [Taschenbuchsonderausgabe]. München; Zürich: Piper, 2003. - 164 S. (Serie Piper; 3929) ISBN 3-492-23929-3

dass. [Tonträger]. Donata Höffer liest Sándor Márai, Das Vermächtnis der Eszter. [Ungekürzte Lesung]. [Berlin]: Parlando, 2002. - 2 Tonkassetten. (Edition Christian Brückner) ISBN 3-935125-06-2 
Wandlungen einer Ehe. Roman. Aus dem Ungarischen von Christina Viragh. München; Zürich: Piper, ${ }^{7} 2003$. - 460 S. ISBN 3-492-04485-9 EST: Az igazi

dass. München: Piper, 2005. - 464 S. (Serie Piper; 4554) ISBN 3-492-24554-4 dass. [Tonträger]. Ungekürzte Lesung. Sprecher: Charles Brauer u.a. Hamburg: Hörbuch Hamburg, 2003. - 12 CDs. ISBN 3-89903-129-6

Der Wind kommt von Westen. Amerikanische Reisebilder. [Aus dem Ungarischen von Artur Saternus]. München: Langen Müller Verlag, 2000. - 200 S. ISBN 3-7844-2795-2

dass. München; Zürich: Piper, 2002. - 198 S. (Serie Piper; 3406) ISBN 3-49223406-2

dass. [Tonträger]. Gelesen von Peter Fricke. München: Herbig, 2001. - 2 Tonkassetten. ISBN 3-7844-5035-0

Das Wunder des San Gennaro. Roman. Aus dem Ungarischen von Tibor Simányi. München: Piper, 2004. - 258 S. (Serie Piper; 7044) ISBN 3-492-27044-1 EST: San Gennaro vére

Zeltner, Ernö: Sándor Márai. Ein Leben in Bildern. München; Zürich: Piper, 2001. - 228 S. ISBN 3-492-04350-X

dass. München: Piper, 2005. - 228 S. (Serie Piper; 4238) ISBN 3-492-24238-3

\section{Márton, Franz}

Friedenssehnsucht der Liebe. Gedichte. Aus dem Ungarischen übertragen von Erika Scharf. Temeswar: Mirton, 2004. - 35 S. ISBN 973-661-295-3

\section{Márton László (1959)}

Die schattige Hauptstraße. Roman. Aus dem Ungarischen von Agnes Relle. Wien: Zsolnay, 2003. - 164 S. ISBN 3-552-05221-6 EST: Árnyas föutca

Die wahre Geschichte des Jacob Wunschwitz. Roman. Aus dem Ungarischen von HansHenning Paetzke. München: Deutscher Taschenbuch Verlag, 2002. - 363 S. (dtv; 12984) ISBN 3-423-12984-0 EST: Jacob Wunschwitz igaz története

\section{Méhes, György (1916)}

Siebenbürger Millionäre. Die Keller-Dynastie - Eine Familiensaga. Aus dem Ungarischen von Géza Deréky. Frankfurt a. M.; München; London; New York: Weimarer SchillerPresse, 2005. - 410 S. ISBN 3-86548-330-5 EST: Kolozsvári milliomosok 


\section{Méhes Károly (1965)}

Zwei Bärte / Von der Erhaltung der Materie. A szakáll - másodszor / Nem vész el, csak átalakul. Zwei Erzählungen. Aus dem Ungarischen von György Buda. Klagenfurt: Wieser Verlag, 2002. - 158 S. (Edition Zwei) ISBN 3-85129-372-X

Mirtse, Agnes (1938-2000)

Wunschbrüchig /vágy-zavar. Gedichte und Prosa. Deutsch und Ungarisch. Herausgegeben und mit einem Nachwort von Christine Tresch und Elisabeth Wandeter-Deck. Zürich: LimmatVerlag, 2004. - 141 S. ISBN 3-85791-452-1

\section{Molnár Ferenc (1878-1952)}

Die Jungen von der Paulstraße. Aus dem Ungarischen von Edmund Alkalay. Budapest: Corvina, 2002. - 212 S. ISBN 963-13-5180-7 EST: A Pál utcai fiúk

dass. Wien: Ueberreuter, 2005. - 202 S. ISBN 3-8000-5199-0

\section{Nádas, Péter (1942)}

Der eigene Tod. Aus dem Ungarischen von Heinrich Eisterer. Göttingen: Steidl, 2002. 224 S. ISBN 3-88243-838-X EST: Halálaim

Freiheitsübung und andere kleine Prosa. Aus dem Ungarischen von Ruth Futaky, Zsuzsanna Gahse, László Kornitzer und Ilma Rakusa. Berlin: Berlin Verlag, 2004. - 210 S. ISBN 38270-0533-7

Schöne Geschichte der Fotografie. Novelle. Aus dem Ungarischen von Ákos Doma. Berlin: Berlin Verlag, 2001. - 131 S. ISBN 3-8270-0401-2 EST: A fotográfia szép története

dass. Berlin: Berliner Taschenbuch Verlag, 2005. - 131 S. (BvT; ) ISBN 3-83330254-2

\section{Nagy, Gáspár (1949)}

Hullámzó vizeken kereszt. Über wogenden Wassern ein Kreuz. Aus dem Ungarischen von Paul Kárpáti. Szentendre: Vincze Papírnyomó Műhely, 2000.

\section{Örkény, István (1912 - 1979)}

Minutennovellen. Ausgewählt und aus dem Ungarischen übersetzł von Terézia Mora. Mit einem Nachwort von György Konrád. Frankfurt a. M.: Suhrkamp, 2002. - 163 S. (Bibliothek Suhrkamp; 1358) ISBN 3-518-223548-5 EST: Egyperces novellák 
Pap, Károly (1897-1945)

Azarel. Roman. Aus dem Ungarischen von Hans Skirecki. München: Luchterhand, 2004. 303 S. ISBN 3-630-871157-7 EST: Azarel

\section{Parti Nagy, Lajos (1953)}

Meines Helden Platz. Aus dem Ungarischen von Terézia Mora. München: Luchterhand Literaturverlag, 2005. - 300 S. ISBN 3-630-87158-5 EST: Hösöm tere

\section{Petöfi, Sándor (1823-1849)}

Held János. Eine deutsche Nachdichłung des ungarischen epischen Gedichtes János vitéz. [Aus dem Ungarischen übertragen von Martin Remané]. Zweisprachige Ausgabe. Budapest: Corvina, 2001. - 153 S. ISBN 963-13-4993-4

\section{Rakovszky, Zsuzsa (1950)}

Familienroman. Gedichte. Aus dem Ungarischen und mit einem Nachwort von Zsuzsanna Gahse. Wien: Edition Korrespondenzen, 2002. - 97 S. ISBN 3-902113-12-X

Im Schatten der Schlange. Roman. Aus dem Ungarischen von Ernö Zeltner. München: Goldmann Verlag, 2005. - 575 S. (btb; 73196) ISBN 3-442-73196-8 EST: A kigyó árnyéka

\section{Schein, Gábor (1969)}

Lazarus! [Aus dem Ungarischen von Wilhelm Droste]. Stuttgart: Merz und Akademie Schloß Solitude, 2004. - 131 S. (Reihe Literatur) ISBN 3-929085-95-X

\section{Schima, Melinda}

Atmen. Philosophische Gedichte. Deutsch /Ungarisch. Wien: Edition Doppelpunkt - Verlag der Autoren, 2001. - 110 S. ISBN 3-85273-110-0 EST: Lélegzet

Székely, János (1901 - 1958)

Verlockung. Roman. Aus dem Ungarischen von Ita Szent-lványi. München: SchirmerGraf Verlag, 2005. - 816 S. ISBN 3-86555-015-0 EST: Kisértés

\section{Szepes, Mária (1908)}

Der rote Löwe. Roman der Esoterik im Abendland. Aus dem Ungarischen von Gotffried Feidel. Überarbeitete Neuausgabe. Bern: Fischer Media, 2000. - 575 S. ISBN 3-85681430-2 EST: A vörös oroszlán

dass. Vorwort zur Neuausgabe von Hans Joachim Alpers. Überarbeitete Neuausgabe. München: Heyne, 2002. - 685 S. (Heyne Science-fiction und Fantasy; 9603: Meisterwerke der Fantasy) 
dass. München; Zürich: Piper, 2004. - 685 S. (Serie Piper; 8543: Piper Fantasy) ISBN 3-492-28543-0

\section{Szerb, Antal ( 1901 - 1945)}

Das Halsband der Königin. Übersetzł von Alexander Lenard. Überarbeitet von Ernö und Renate Zeltner. München: Deutscher Taschenbuch Verlag, 2005. - 288 S. (dtv Belletristik; 13365) ISBN 3-423-13365-1 EST: A királyné nyaklánca

Die Pendragon-Legende. Roman. Übersetzt von Susanna Großmann-Vendrey. Mit einem Nachwort von György Poszler. München: Deutscher Taschenbuch Verlag, 2004. - 311 S. (dtv premium; 24425) ISBN 3-423-24425-9 EST: A Pendragon-legenda

dass. [Tonträger]. Gekürzte Lesung. Gelesen von Heikko Deutschmann. Hamburg: Hörbuch Hamburg, 2005. - 5 CDs. ISBN 3-89903-169-5

Reise im Mondlicht. Roman. Aus dem Ungarische von Christina Viragh. Mit einem Nachwort von Péter Esterházy. München: Deutscher Taschenbuch Verlag, 2003. - 258 S. (dtv premium; 24370) ISBN 3-423-24370-8 EST: Utas és holdvilág

dass. [Tonträger]. Gekürzte Lesung. Gelesen von Heikko Deutschmann. Hamburg: Hörbuch Hamburg, 2004. - 5 CDs. ISBN 3-89903-160-1

dass. [Tonträger]. Hörspiel. Sprecher: Ulrich Noethen, Sebastian Rudolph, Irina Wanka. München: DHV - Der Hörverlag, 2005. - 2 CDs. ISBN 3-89940-496-3

\section{Sziii, Ferenc (1958)}

Sturzlicht. Zwei Bücher zu langen Unfällen. Aus dem Ungarischen von Andrea Seidler und György Buda. Graz: Literaturverlag Droschl, 2005. - 80 S. ISBN 3-85420-677-1

\section{Tolnai, Ottó (1940)}

Ich kritzelte das Akazienwäldchen in mein Heft. Vier Erzählungen. Aus dem Ungarischen von György Buda und Géza Deréky. Wien, Lana: edition per procura, 2002. - 167 S. (abrasch; 3) ISBN 3-901118-49-7

Eine Postkarte an Don Dukay. Neun Geschichten aus der Provinz. Aus dem Ungarischen von György Buda. Berlin: DAAD Berliner Künstlerprogramm, 2005. - 110 S. (Spurensicherung; 15) ISBN 3-89357-112-4

\section{Tótfalusi, István (1936)}

Opernmärchen. Übersetzł von Andreas Neutsch. III. von Angelika Gausmann. Schloß Hamborn: Möllmann, 2001. - 428 S. ISBN 3-931156-69-9 
Vámos, Miklós (1950)

Buch der Väter. Roman. Aus dem Ungarischen übersetzt, mit Anmerkungen und einem Nachwort versehen von Ernö Zeltner. München: btb Verlag, 2004. - 511 S. ISBN 3-44275118-7 EST: Apák könyve

Várkonyi, Zsuzsa F. (1948)

Für wen du lebst. Ein Mädchenroman aus Männerzeiten. Aus dem Ungarischen übersetz† von Elisabeth Brunner-Sobanski, Konstanz: Hartung-Gorre-Verlag, 2005. - 224 S. ISBN 3-89649968-8 EST: Férfiidők lényregénye

Vörös, István (1964)

Die leere Grapefruit. Gedichte. Aus dem Ungarischen von Zsuzsanna Gahse. Wien: Edition Korrespondenzen, 2004. - 96 S. ISBN 3-902113-34-0

Vörösmarty, Mihály (1800-1855)

Die Mondscheinnacht. A holdvilágos éj. Deutsch von Paul Kárpáti. Budapest: Argumentum Kiadó, 2002. - 163 S. (Medaillon; 2) ISBN 963-463-117-4

Zilahy, Lajos (1891 - 1974)

Was mein Herz begehrt. Roman. Aus dem Ungarischen von Eta Neumann-Veith und Andrea Seidler. München: Diana Verlag, 2005. - 544 S. ISBN 3-453-26519-X EST: Két fogoly

\section{Zilahy, Péter (1970)}

Drei. Aus dem Ungarischen übersetzł von Terézia Mora und Agnes Relle. Herausgegeben von Jean-Baptiste Joly. Stuttgart: Akademie Schloß Solitude, 2003. - 151 S. (Edition Solitude) ISBN 3-929085-83-6

Die letzte Fenstergiraffe. Ein Revolutions-Alphabet. Aus dem Ungarischen von Terézia Mora. Mit einem Vorwort von Ingo Schulze. Frankfurt a. M.: Eichborn, 2004. - 180 S. ISBN 38218-0755-5 EST: Az utolsó ablakzsiráf

\section{Zsolt, Béla (1895 - 1949)}

Eine seltsame Ehe. Roman. Aus dem Ungarischen von Angelika Máté. Frankfurt a. M.: Neue Kritik, 2001. - 364 S. ISBN 3-8015-0355-0 EST: A dunaparti nő

Neun Koffer. Roman. Aus dem Ungarischen von Angelika Maté. Mit einem Nachwort von Ferenc Köszeg. [Ungekürzte Ausgabe]. München: Deutscher Taschenbuch Verlag, 2002. - 392 S. (dtv; 13013) ISBN 3-423-13013-X EST: Kilenc koffer 


\section{Sammlungen}

\section{Blaschtik, Éva (Hrsg.)}

Durst. Eine zweisprachige Anthologie ungarischer Liebesgedichte. Budapest: Corvina, 2002.

- 213 S. ISBN 963-13-5202-1

Endre Ady, Mihály Babits, Bálint Balassi, Zsófia Balla, Dániel Berzsenyi, Mihály Csokonai Vitéz, Sándor Csoóri, Jenő Dsida, Anna Hajnal, Jenő Heltai, Gyula Illyés, Flóra Imre, Attila József, Ferenc Juhász, Gyula Juhász, Margit Kaffka, Sándor Kányádi, Lajos Kassák, Ferenc Kazinczy, Sándor Kisfaludy, Ferenc Kölcsey, Dezső Kosztolányi, László Lator, László Nagy, Ágnes Nemes Nagy, Ottó Orbán, Sándor Petöfi, György Petri, János Pilinszky, Miklós Radnóti, Sándor Rákos, Zsuzsa Rakovszky, György Somlyó, Lörinc Szabó, Árpád Tóth, János Vajda, Mihály Vörösmarty, Sándor Weöres, Zoltán Zelk

\section{Buda, György (Hrsg.)}

Thema Ungarn. Podium Doppelheft 135/136. Wien: Mai 2005. ISBN 3-902054-35-2 Csaba Báthori, György Berkovits, László Darvasi, Lajos Grendel, Mila Haugová, Zoltán Hizsnyai, Imre Kertész, László Krasznahorkai, Endre Kukorelly, Zsolt Láng, Sándor Márai, Károly Méhes, Lajos Parti Nagy, Zsuzsa Rakovszky, Ferenc Sziij, Sándor Tatár, György Timár, Ottó Tolnai, Mátyás Varga, Pál Závada

\section{Echterer, Mercedes (Hrsg.)}

Budapest. Klagenfurt: Wieser Verlag, 2001. - 270 S. (Europa erlesen) ISBN 3-85129350-9

Tibor Déry, István Eörsi, Virág Erdős, Attila József, Imre Kertész, Mihály Kornis, Dezső Kosztolányi, Gyula Krúdy, Paul Lendvai, Zsigmond Móricz, István, Örkény, Sándor Petôfi, Miklós Radnóti, Róbert Reiter, György Sebestyén, Emil Szittya, Dezsó Tandori

\section{Gehrisch, Peter; Helbig, Axel (Hrsg.)}

Das Land Ulro nach der Schließung der Zimtläden. Stimmen aus Deutschland, Polen, Tschechien und Ungarn. [Übertragungen aus dem Ungarischen von Csaba Báthori]. Dresden: Sandstein, 2000. - 120 S. (Sonderveröffentlichung von Ostragehege - Zeitschrift für Literatur und Kunst) ISBN 3-930382-48-2

Zsófia Balla, Csaba Báthori, Endre Kukorelly, László Lator, Lajos Parti Nagy, György Petri, Zsuzsa Takács, Dezső Tandori

\section{Hahn, Jaroslava und Ralph (Hrsg.)}

Transkarpatien. Klagenfurt: Wieser, 2004. - 250 S. (Europa erlesen) ISBN 3-85129-427-0 Béla Illés, Ferenc Kölcsey, Sándor Petöfi, Móricz Zsigmond 


\section{Hellwig-Schmid, Regina (Hrsg.)}

DonauWelten. Ein Flußbuch. Ein Projekt des Kunstknoten e.V. der edition lichtung. Viechtach: Lichtung, 2000. - 312 S. ISBN 3-929517-37-X

Antal András Deák, Zsófia Balla, Péter Esterházy, László F. Földényi, Mihály Kornis

\section{Kirnbauer, Franz (Hrsg.)}

Literatur überwindet Grenzen.

1. Literaturwettbewerb für junge Autoren zum Thema Verzweiflung: Österreich, Slowenien und Ungarn. Graz: Perplex, 2000. - 122 S. ISBN 3-901510-04-4

2. Literaturwettbewerb für junge Autoren zum Thema Grenzen-Los: Literaturwettbewerb für junge Autoren zum Thema Österreich, Deutschland, Slowenien, Tschechien, Ungarn. Graz: Perplex, 2001. - 168 S. ISBN 3-901510-05-2

3. Literaturwettbewerb für junge Autoren zum Thema Ziel-Los: Österreich, Deutschland, Slowenien, Kroatien, Südtirol/Italien, Ungarn, Tschechien, Slowakei, Rumänien. Graz: Perplex. - 2001. - 217 S. ISBN 3-901510-07-9

4. Literaturwettbewerb für junge Autoren zum Thema Lebens $(t)$ raum: Deutschland, Estland, Italien, Jugoslawien, Kroatien, Lettland, Österreich, Polen, Rumänien, Schweiz, Slowakei, Slowenien, Tschechien, Ungarn. Graz: Perplex, 2003. - 226 S. ISBN 3-901510-0-9

5. Literaturwettbewerb für junge Autoren zum Thema Bereicherung: Bosnien und Herzegowina, Deutschland, Estland, Italien, Kroatien, Lettland, Litauen, Luxemburg, Österreich, Polen, Rumänien, Russland, Schweden, Serbien und Montenegro, Slowenien, Tschechien, Ungarn, USA. Graz: Perplex, 2004. - 186 S. ISBN 3-901510-13-3

\section{Kosztics-Gyurkó, Andrea (Hrsg.)}

Das Buch der Ränder. Roma-Lyrik. Eine Auswahl Deutsch-Romanes. Veränderte Neuauflage. Klagenfurt; Wien; Ljubljana; Sarajevo: Wieser Verlag, [2004]. - 165 S. (Wortlandstreicher) ISBN 3-85129-456-4

József Choli Daróczi, Gyula Horváth, Mónika Kalányos, József Kovács Hontalan, Gusztáv Nagy, József Rigó, Zsolt Szolnoki Csanya, Endre Bihari

\section{Pölzl, Birgit (Hrsg.)}

Himmel. Wien: Edition Korrespondenzen, 2003. - 124 S. ISBN 3-902113-23-5

Zsófia Balla, István Eörsi

\section{Richter, Barbara (Hrsg.)}

Literatur Total. [Medienkombination]. Autoren lesen in der daadgalerie. Berlin: Deutscher Akademischer Austauschdienst - Berliner Künstlerprogramm, 2002. - 2 CDs mit Booklet. (Spurensicherung; 8) ISBN 3-89357-102-7

Zsófia Balla, László Darvasi 
Rübberdt, Irene; Schlosser, Christine (Hrsg.)

Das Buch der Ränder. Die Unsichtbaren - Ungarische Prosa jenseits der Staatsgrenzen. Klagenfurt; Wien; Ljubljana; Sarajevo: Wieser Verlag, [2004]. - 249 S. (Wortlandstreicher) ISBN 3-85129-470-X

Attila Balázs, Károly D. Balla, Éva Berniczky, Ádám Bodor, Antal Fülöp, Sándor Gál, Nándor Gion, Lajos Grendel, Zsolt Láng, István Szilágyi, Ottó Tolnai

Ruoss, Siegfried (Hrsg.)

Märchen und Sagen entlang der Donau. Tübingen: Silberburg, 2002. - 222 S. ISBN 387407-514-1

\section{SakoHoess, Renata; Hackermüller, Rotraut (Hrsg.)}

Bratislava. Klagenfurt: Wieser Verlag, 2001. - 253 S. (Europa erlesen) ISBN 3-85129-319-3 Lajos Grendel, Gyula Reviczky, György Sebestyén

\section{Stahl, Barbara (Hrsg.)}

Erinnern und Vergessen. Ein ungarisch-deutsches Dichtertreffen. Forum für neue Kunst, Literatur und Musik - Herrenhaus 2001. Übersetzt von Kristin Schwamm. Hannover: Revonnah Verlag, 2001. - 79 S. (Herrenhaus; 1) ISBN 9-934818-31-5

László Darvasi, László Krasznahorkai, László Márton

\section{Tobler, Barbara (Hrsg.)}

Mattersburg. Literarische Stadtbilder. Weitra: Bibliothek der Provinz, 2002. - 107 S. ISBN 3-85252-509-8

György Dalos, Károly Méhes, Lajos Parti Nagy

Wieser, Lojze; Pittler, Andreas P. (Hrsg.)

Weiter Osten. Klagenfurt: Wieser Verlag, 2003. - 203 S. (Europa erlesen) ISBN 3-85129400-9

István Eörsi, Lajos Kassák, Gyula Krúdy, Dezső Tandori

Wieser, Margot (Hrsg.)

Stiller Aufbruch. Frauen in Ungarn erzählen. Mit einem Vorwort von Mária Ember. Wien: Milena Verlag, 2001. - 292 S. (Reihe Dokumentation; 21) ISBN 3-85286-08-5

Der himmelhohe Baum. Ungarische Volksmärchen. Literarische Bearbeitung Elek Benedek und Gyula Illyés. [Aus dem Ungarischen übertragen von Gertrud Dubovitz]. [Budapest]: Corvina, ${ }^{5}$ 2001. - 64 S. ISBN 963-13-4991-8 
Három Holló. Zeitschrift für ungarische Kultur (ab 2002 Drei Raben. Zeitschrift für ungarische Kultur). ISSN 1586-8583

Heft 1, Dezember 2000: Kaffeehaus als Kultur

Heft 2, September 2001: Frauen erinnern

Heft 3, März 2002: $\quad$ Das ungarische Berlin

Heft 4/5, Februar 2003: Ady

Heft 6, März 2004: Das ungarische Wien

Heft 7, März 2005: $\quad$ Ungarische Inseln

Heft 8, Dezember 2005: Attila József 
Autoren, die in deutscher bzw. in anderen Sprachen schreiben

Báger, Gusztáv (1938)

Heisskaltes Wasser - Die Nacht eines Beamten. Gedichte. Übersetzt von Imre Máté. Schweinfurt: Wiesenburg, 2001. - 89 S. ISBN 3-932497-65-1

\section{Bánk, Zsuzsa (1965)}

Heißester Sommer. Erzählungen. Frankfurt a. M.: S. Fischer, 2005. - 152 S. ISBN 3-10005221-8

dass. [Tonträger]. Karoline Eichhorn liest. Ungekürzte Lesung. Berlin: Argon-Verlag, 2005. - 4 CDs. ISBN 3-87024-005-9

Der Schwimmer. Roman. Frankfurt a. M.: Fischer, 2002. - 284 S. ISBN 3-10-005220-X

dass. Frankfurt a. M.; Wien; Zürich: Büchergilde Gutenberg, 2003. - 284 S. ISBN 3-7632-5363-7

dass. Frankfurt a. M.: Fischer Taschenbuch-Verlag, ،2004. - 284 S. (Fischer TB; 15248) ISBN 3-596-15248-8

dass. [Tonträger]. Gelesen von der Autorin und Eva Gosciejewiecz. [Autorisierte Lesefassung]. München: DHV - Der Hörverlag, 2003. - 4 CDs. ISBN 3-89940$121-2$

Brachfeld, Siegfried (1917- 1978)

Warum ist die Krone schief? Ungarn-Glossen. Budapest: Pester Lloyd-Verlag, 2003. - 170 S. ISBN 963-210-702-0

\section{Csiba, László (1949)}

Das Lachen der Fische. Gedichte. Mit einem Essay von Wilhelm Bartsch. Halle an der Saale: János Stekovics, 2003. - 110 S. (Edition Steko; 21) ISBN 3-89923-013-2

Doma, Ákos (1963)

Der Müßiggänger. Roman. Hamburg: Rotbuch-Verlag, 2001. - 348 S. ISBN 3-434-53075-4

Flack, Zsuzsanna (1946)

Die Grillen. Gedichte. Dresden: Dresdner Verlag, 2000. - 54 S. ISBN 3-933109-08-6 
Nicht gilt, was nicht geschah. Gedichte. Dresden: Christoph Hille, 2004. - 88 S. ISBN 3932858-77-8

Gahse, Zsuzsanna (1946)

Berganza. Erzählung. Hamburg: Europäische Verlags-Anstalt, 1999. - 101 S. ISBN 3434-50477-X

Calgary. April 1997. Warmbronn: Ulrich Keicher, 1999. - [20] S. (Warmbronner Edition; 17) ISBN 3-932843-10-X

durch und durch. Müllheim, Thur in drei Kapiteln. Wien: Edition Korrespondenzen, 2004. - 174 S. ISBN 3-902113-28-6

Nichts ist wie oder Rosa kehrt nicht zurück. Roman. Hamburg: Europäische Verlags-Anstalt, 1999. - 160 S. ISBN 3-434-50469-9

in: Annen, Anna Margrit: Gleichzeitig. [Texte von Monika-Maria Herzog; Zsuzsanna Gahse]. Luzern: Ed. Howeg, 2003. - 37 S. ISBN 3-85736-230-8

in: Fellbacher Magie. Literarische Gänge. Fellbach: Stadt Fellbach, 2002. - 138 S. (Fellbacher Hefte; 10) ISBN 3-9807598-2-2

in: Kiss Horváth, Monika: Bar in Italia 1987 - 1998. Zürich; Berlin; New York: Edition Frey, 1999. - [132] S. ISBN 3-905509-27-X

dies.; Rütimann, Christoph: Kaktus Haben. [Alpnach Dorf]: Wallimann, 2001. - 82 S. ISBN 3-908713-12-9

dies.; Braitenber, Valentin; Sabin, Stefana: Wörter, Wörter, Wörter! Göttingen: Wallstein, 1999. - 40 S. (Göttinger Sudelblätter) ISBN 3-89244-334-3

Keren, Rivka (1946)

Anatomie einer Rache. Roman. Aus dem Hebräischen von Helene Seidler. Gerlingen: Bleicher, 2001. - 252 S. ISBN 3-88350-116-6

Kiss, Elemér Tibor (1942)

Wege zum Lächeln. Mit Zeichnungen von István Száz. Blieskastel: Gollenstein Verlag, 2002. - 197 S. ISBN 3-935731-04-3 
Kövary, Georg (1922)

Melancholie des Markknochens. Robin Food's gastrophische Reisen durch das Land der Magyaren. Der erste deutschsprachige Restaurantführer Ungarns. Budapest: Pester Lloyd Verlag, 2002. - 250 S. ISBN 963-8116-4

Träume deutsch - mit ungarischen Untertiteln. Kaffeehausgeschichten. Budapest: Pester Lloyd-Verlag, 2002. - 77 S. ISBN 963-009529-7

\section{Kristóf, Ágota (1935)}

Die Analphabetin. Autobiographische Erzählung. Aus dem Französischen von Andrea Spingler. Zürich: Ammann Verlag, 2005. - 75 S. (Meridiane; 83) ISBN 3-250-60083-0

dass. [Tonträger]. Sprecher: Hannelore Hoger. Köln: Random House Audio, 2005. ISBN 3-86604-033-4

Hier. Roman. Ditzingen: Philipp Reclam jun., 2002. - 139 S. (Reclams UB; 9096) ISBN 315-009096-2

Das große Heft. [Tonträger]. Hörspiel. München: Der Hörverlag, 2001. - 2 Tonkassetten. ISBN 3-89584-871-9

\section{Kürthy, Ildikó von (1968)}

Blaue Wunder. Roman. Reinbek bei Hamburg: Wunderlich, 2004. - 251 S. ISBN 3-80520776-X

Freizeichen. Roman. Reinbek bei Hamburg: Wunderlich, ${ }^{5} 2004$. - 240 S. ISBN 3-8052$0750-6$

dass. Augsburg: Weltbild, 2004. - 231 S. ISBN 3-8289-7541-0

dass. Reinbek bei Hamburg: Rowohlt Taschenbuch Verlag, 2004. - 231 S. (rororo; 23614) ISBN 3-499-23614-1

dass. [Tonträger]. Gelesen von Svenja Pages. [Autorisierte Lesefassung]. München: DHV - Der Hörverlag, 2003. - 2 CDs. ISBN 3-89940-193-X

Herzsprung. Roman. Wunderlich, ${ }^{5} 2002$ - - 256 S. ISBN 3-8052-0711-5

dass. [Limitierte Sonderausgabe]. Reinbek bei Hamburg: Rowohlt Taschenbuch Verlag, 2004. - 247 S. (rororo; 23753) ISBN 3-499-23753-9 
Karl Zwerglein. Eine Geschichte für Zauberinnen und Zauberer. Reinbek: RowohltTB, 2003. - 122 S. (rororo roffuchs; 21235) ISBN 3-499-21235

dies. liest Karl Zwerglein. Eine Geschichte für Zauberinnen und Zauberer. [Tonträger]. [Autorisierte Lesefassung]. München: Der Hörverlag, 2004. - 1 CD. ISBN 3-89940-305-3

Mondscheintarif. Roman. Wunderlich, 2002. - 144 S. ISBN 3-8052-0737-9

dass. [Einmalige Sonderausgabe]. Reinbek bei Hamburg: Rowohlt Taschenbuch Verlag, 2004. - 141 S. (rororo; 23479) ISBN 3-499-23479-3

dass. Reinbek bei Hamburg: Rowohlt Taschenbuch Verlag, ${ }^{35} 2003$. - 144 S. (rororo; 22637) ISBN 3-499-22637

Máté, Imre (1934)

Der Marder kehrt zurück. Gedichte. Schweinfurt: Wiesenburg, 2002. - 118 S. ISBN 39323497-69-4

Mora, Terézia (1971)

Alle Tage. Roman. München: Luchterhand Literaturverlag, 2004. - 429 S. ISBN 3-63087185-2

dass. Frankfurt a. M.; Wien; Zürich: Büchergilde Gutenberg, [2005]. - 429 S. ISBN 3-7632-5548-6

dass. [Tonträger]. Gelesen von Eva Mattes. [Köln]: Random House Audio, 2005. - 10 CDs. ISBN 3-89830-950-9

Seltsame Materie. Erzählungen. Berlin: Rowohlt Berlin, 1999. - 254 S. ISBN 3-498-04471-0 dass. Reinbek bei Hamburg: Rowohlt Taschenbuch Verlag, 2000. - 254 S. (rororo; 22894) ISBN 3-499-22894-7

in: Beste Deutsche Erzähler 2003. Herausgegeben von Hubert Winkels. München: DVA, 2003. - 320 S. ISBN 3-421-05625-0

\section{Nagel, Ivan (1931)}

Das Falschwörterbuch. Krieg und Lüge am Jahrhundertbeginn. Berlin: Berliner Taschenbuch Verlag, 2004. - 138 S. (BvT; 105) ISBN 3-8333-0105-8 
Streitschriften. Politik - Kulturpolitik - Theaterpolitik 1957-2001. Berlin: Siedler, 2001. 222 S. ISBN 3-88680-731-2

Roger Willemsen - das Bühnengespräch mit Ivan Nagel. Live aus dem Deutschen Schauspielhaus in Hamburg. Hamburg: Hoffmann und Campe, 2001. - 1 CD. ISBN 3-45530217-3

\section{Oertelt, Evelin}

Ungarn - nicht nur Paprika und Piroska. Ein humoriger Erlebnisbericht. Herne: Gabriele Schäfer Verlag, 2004. - 206 S. ISBN 3-933337-33-X

\section{Rakusa, Ilma (1946)}

Love after Love. Acht Abgesänge. Frankfurt a. M.: Suhrkamp, 2001. - 54 S. (es; 2251) ISBN 3-518-12251-7

in: Melzer, Gerhard (Hrsg.): Es liegt was in der Luft. Die Himmel Europas. Graz: Literaturverlag Droschl, 2003. - CL S. ISBN 3-85420-624-0

\section{Vizinczey, Stephen (1933)}

Die zehn Gebote eines Schriftstellers. Essays zur Weltliteratur. Aus dem Englischen von Melanie Walz und Bernhard Robben. München: SchirmerGraf Verlag, 2004. - 281 S. ISBN 3-86555-007-X

Wie ich lernte, die Frauen zu lieben. Die amourösen Erinnerungen des András Vajda. Aus dem Englischen von Carina von Enzenberg. München: SchirmerGraf Verlag, 2004. 306 S. ISBN 3-86555-008-8

\section{Viragh, Christina (1953)}

Pilatus. Roman. Zürich: Ammann Verlag, 2003. - 235 S. (Meridiane; 56) ISBN 3-25060056-3 


\section{Ungarndeutsche Autoren}

\section{Michaelis, Josef (1955)}

Treibsand. Ausgewählte Texte 1976-2001. Mit einem Nachwort von Helmut Rudolf. Budapest: VudAK, 2004. - 205 S. (VudAK-Bücher: Reihe Literatur; 8) ISBN 963-833308-1

Zauberhut. 3., erw. Aufl. Budapest: Landesselbstverwaltung der Ungarndeutschen, 2001. - 106 S. ISBN 963-00-9030-9

\section{Raile, Stefan (1937)}

Die gehenkten Puppen. Roman. Herdecke: Scheffler, 2001. - 213 S. ISBN 3-89704-153-7

Die Melone im Brunnen. Roman. Halle: Mitteldeutscher Verlag, 2004. - 304 S. ISBN 389812-245-X

Rittinger, Engelbert (1929-2000)

Verschiedene Verhältnisse. Ausgewählte Werke. Budapest: VudAK, 2001. - 239 S. (VudAKBücher: Reihe Literatur; 7) ISBN 963-8333-05-7 

II. Sachliteratur 


\section{Philosophie}

\section{Albert, Sándor}

Übersetzung und Philosophie. Wissenschaftsphilosophische Probleme der Übersetzungstheorie - Die Fragen der Übersetzung von philosophischen Texten. Aus dem Ungarischen übersetzt von László Valaczkai. Mitarbeit an der Textgestaltung: Ágota Kozma. Wien: Edition Praesens, 2001. - 284 S. ISBN 3-7069-0080-7

\section{Fehér, István M. (Hrsg.)}

Kunst, Hermeneutik, Philosophie. Das Denken Hans-Georg Gadamers im Zusammenhang des 20. Jahrhunderts. Akten des Internationalen Symposiums Budapest, 19.-22. Oktober 2000. Heidelberg: Universitätsverlag Carl Winter, 2003. - 235 S. (Beiträge zur Philosophie) ISBN 3-8253-1451-0

Hogrebe, Wolfram (Hrsg.)

Philosophia Hungarica. Profile zeitgenössischer philosophischer Forschung in Ungarn.

Würzburg: Königshausen und Neumann, 2001. - 339 S. ISBN 3-8260-2158-4 


\section{Geschichte}

Das Schicksal der Deutschen in Ungarn. Dokumentation der Vertreibung der Deutschen aus Ost-Mitteleuropa. München: Deutscher Taschenbuch Verlag, 2005. - 336 S. (dtv Kultur und Geschichte; 34186) ISBN 3-423-34186-6

\section{Adriányi, Gabriel}

Geschichte der katholischen Kirche in Ungarn. Köln; Weimar; Wien: Böhlau Verlag, 2004. - XIV, 314 S. (Bonner Beiträge zur Kirchengeschichte; 26) ISBN 3-412-10404-3

Kleine Kirchengeschichte Ungarns. Herne: Gabriele Schäfer Verlag, 2003. - 135 S. (Studien zur Geschichte Ungarns; 5) ISBN 3-933337-30

Die Ostpolitik des Vatikan 1958 - 1978 gegenüber Ungarn. Der Fall Kardinal Mindszenty. Herne: Gabriele Schäfer Verlag, 2003. - 185 S. (Studien zur Geschichte Ost- und Ostmitteleuropas; 3) ISBN 3-933337-29-1

\section{Almai, Frank; Fröschle, Ulrich (Hrsg.)}

Deutsche in Ungarn - Ungarn und Deutsche. Interdisziplinäre Zugänge. Dresden: w.e.b. Universitätsverlag / Buchhandel Eckehard Richter \& Co., 2003. - XVIII, 183 S. (Mitteleuropa-Studien; 6) ISBN 3-935712-07-3

\section{Aufricht, Josef}

Deutsche im ersten Stadtbezirk von Ofen. Budapest: Deutscher Kulturverein, 2004. - 355 S. ISBN 963-214-229-2

\section{Bachmaier, Peter; Blehova, Beata (Hrsg.)}

Der kulturelle Umbruch in Ostmitteleuropa. Der Transformationsprozess und die Bildungsund Kulturpolitik Tschechiens, der Slowakei, Polens und Ungarns im Kontext der internationalen Beziehungen. Frankfurt a. M.; Berlin; Bern; Bruxelles; New York; Oxford; Wien: Peter Lang, 2005. - 342 S. (St. Pöltner Osteuropa-Studien; 3) ISBN 3-631-530011-0

\section{Bahlcke, Joachim}

Ungarischer Episkopat und Österreichische Monarchie. Von einer Partnerschaft zur Konfrontation (1686-1790). Stuttgart: Franz Steiner Verlag, 2005. - 516 S. (Forschungen zur Geschichte und Kultur des östlichen Mitteleuropa; 23) ISBN 3-515-08764-8 


\section{Barcsay, Ákos}

Herrschaftsantritt im Ungarn des 18. Jahrhunderts. Studien zum Verhältnis zwischen Krongewalt und Ständetum im Zeitalter des Absolutismus. St. Katherinen: Scripta-MercaturaeVerlag, 2002. - VI, 292 S. (Studien zur neveren Geschichte; 2) ISBN 3-89590-120-2

\section{Barth, Bernd-Rainer; Schweizer, Werner (Hrsg.)}

Der Fall Noel Field. Schlüsselfigur der Schauprozesse in Osteuropa 1948-1957. Herausgegeben von Bernd-Rainer Barth und Werner Schweizer in Verbindung mit Thomas Grimm. Kommentiert und übersetzt von Bernd-Rainer Barth.

Bd. 1 Gefängnisjahre 1949-1954. Berlin: BasisDruck, 2005. - XXXVIII, 933 S. + 1 DVD-Video. (Zeitzeugen; 1) ISBN 3-86163-102-4

\section{Beer, Mathias; Seewann, Gerhard (Hrsg.)}

Südostforschung im Schatten des Dritten Reiches. Institutionen - Inhalte - Personen. München: R. Oldenbourg, 2004. - 288 S. (Südosteuropäische Arbeiten; 119) ISBN 3486-57564-3

\section{Bellér, Béla}

Vom Volksbildungsverein zum Volksbund. Geschichte der Deutschen in Ungarn 1933 1938. [Aus dem Madjarischen von Franz Wesner]. Heidelberg: Suevia Pannonica, 2000. - $192 \mathrm{~S}$.

\section{Besymenski, Lew; Völklein, Ulrich}

Die Wahrheit über Raoul Wallenberg. Geheimdokumente und KGB-Veteranen beschreiben die Mission und die Ermordung des schwedischen Diplomaten, der im Zweiten Weltkrieg Ungarns Juden zu retten versuchte. Göttingen: Steidl Verlag, 2000. - 220 S. ISBN 3-88243-712-X

\section{Biegert, Susanne (Hrsg.)}

Von Augustus bis Attila. Leben am ungarischen Donaulimes. Stuttgart: Konrad Theiss, 2000. - 131 S. (Schriften des Limesmuseums Aalen; 53) ISBN 3-8062-1541-3

Bispinck, Henrik u.a. (Hrsg.)

Aufstände im Ostblock. Zur Krisengeschichte des realen Sozialismus. Herausgegeben im Auftrag des Instituts für Zeitgeschichte München/ Berlin und des Zentrums für Zeithistorische Forschung Potsdam. Berlin: Christoph Links Verlag, 2004. - 344 S. ISBN 3-86153-328-6 


\section{Bock-Luna, Birgit}

Reiseleben - Lebensreise. Der ungarische Orientalist Hermann Vámbery (1832-1913) über Zentralasien. Münster: LIT, 2003. - 133 S. (Interethische Beziehungen und Kulturwandel; 55) ISBN 3-8258-7270-X

\section{Breitner-Czuma, Robert}

Die Bedeutung und die Folgen der ungarischen bürgerlich-adligen Reformbewegung von 1848 für die Entwicklung der politischen Struktur Ungarn nach 1988. Berlin: Freie Universität, 2000. - 513 Bl. [Mikrofiche-Ausgabe].

\section{Brockhoff, Evamaria; Jahn, Wolfgang (Hrsg.)}

Bayern - Ungarn. 1000 Jahre. Katalogband. Regensburg: Friedrich F. Pustet, 2001. 407 S. (Veröffentlichungen zur bayerischen Geschichte und Kultur; 43) ISBN 3-7917-1752-9

\section{Brunner, Georg (Hrsg.)}

Ungarn und Europa. Rückblick und Ausblick nach tausend Jahren. München: SüdosteuropaGesellschaft, 2001. - 164 S. (Südosteuropa-Studien; 68) ISBN 3-925450-90-4

\section{Csáky, Moritz; Zeyringer, Klaus (Hrsg.)}

Pluralitäten, Religionen und kulturelle Codes. Innsbruck; Wien; München; Bozen: StudienVerlag, 2001. - 242 S. (Paradigma: Zentraleuropa; 3) ISBN 3-7065-1573-3

\section{Dalos, György}

Ungarn in der Nußschale. Geschichte meines Landes. München: C. H. Beck Verlag, 2004. - 199 S. ISBN 3-406-51032-9

dass. München: Beck, 2005. - 199 S. (Beck'sche Reihe; 1638) ISBN 3-40652810-4

\section{Deutsches Kulturforum östliches Europa (Hrsg.)}

Deutsche und Ungarn - eine besondere Beziehung. Zukunftschance oder Auslaufmodell. Potsdam: Deutsches Kulturforum östliches Europa, 2005. - 89 S. (Potsdamer Bibliothek östliches Europa - Potsdamer Forum; 8) ISBN 3-936168-22-9

\section{Fata, Márta}

Ungarn, das Reich der Stephanskrone, im Zeitalter der Reformation und Konfessionalisierung. Multiethnizität, Land und Konfession 1500-1700. Münster: Aschendorff Verlag, 2000. IX, 359 S. (Katholisches Leben und Kirchenreform im Zeitalter der Glaubensspaltung; 60) ISBN 3-402-02981-2 
dies. (Hrsg.)

Das Ungarnbild der deutschen Historiographie. Stuttgart: Franz Steiner Verlag, 2004. 334 S. (Schriftenreihe des Instituts für donauschwäbische Geschichte und Landeskunde; 13) ISBN 3-515-08428-2

Fazekas, István (Hrsg.)

Kaiser und König. 1526-1918. Eine historische Reise. Österreich und Ungarn 1526- 1918. Ausstellung im Prunksaal der Österreichischen Nationalbibliothek, 8. März bis 1. Mai 2001. Wien: Collegium Hungaricum; Wien: Österreichische Nationalbibliothek, 2001. 204 S. ISBN 963-00-6085-X

Feichtinger, Johannes (Hrsg.)

Habsburg postcolonial. Machtstrukturen und kollektives Gedächtnis. Innsbruck; Wien; München; Bozen: Studien-Verlag, 2003. - 343 S. (Gedächtnis - Erinnerung - Identität; 2) ISBN 3-7065-1886-4

\section{Fischer, Holger (Hrsg.)}

Geschichte Ungarns und Finnlands. Hungarian and Finnish history. Hamburg: Zentrum für Hungarologie im Institut für Finnougristik der Universität Hamburg, 2002. - 1 CD-ROM.

\section{Foitzik, Jan (Hrsg.)}

Entstalinisierungskrise in Ostmitteleuropa 1953-1956. Vom 17. Juni bis zum ungarischen Volksaufstand. Politische, militärische, soziale und nationale Dimensionen. Paderborn; München; Wien; Zürich: Schöningh, 2001. - 393 S. ISBN 3-506-72590-4

\section{Font, Márta}

Geschichtsschreibung des 13. Jahrhunderts an der Grenze zweier Kulturen. Das Königreich Ungarn und das Fürstentum Halitsch-Wolhynien. Stuttgart: Franz Steiner Verlag, 2005. - 48 S. (Abhandlungen der Geistes- und Sozialwissenschaftlichen Klasse / Akademie der Wissenschaften und der Literatur; Jg. 2005, Nr. 3) ISBN 3-515-08715-X

\section{Font, Márta; Szögi, László (Hrsg.)}

Die ungarische Universitätsbildung und Europa. Pécs: Universität, 2001. - 235 S. ISBN 963-641-826-8

\section{Fried, Johannes}

Otto III. und Boleslaw Chrobry. Das Widmungsbild des Aachener Evangeliars, der "Akt von Gnesen" und das frühe polnische und ungarische Königtum. 2., durchgesehene und erweiterte Auflage. Stuttgart: Franz Steiner Verlag, 2001. - 191 S. ISBN 3-515-07502-X 


\section{Gebert, Agathe}

Die Ungarische Akademie der Wissenschaften im Systemwechsel 1986 bis 1994. Zwischen Tradition und Modernisierung. Frankfurt a. M.; Berlin; Bern; Bruxelles; New York; Oxford; Wien: Peter Lang, 2005. - 303 S. (Europäische Hochschulschriften: Reihe 3, Geschichte und ihre Hilfswissenschaften; 1007) ISBN 3-631-52777-2

\section{Geoffroy, René}

Ungarn als Zufluchtsort und Wirkungsstätte deutschsprachiger Emigranten (1933 - 1938) 39). Frankfurt a. M.; Berlin; Bern; Bruxelles; New York; Oxford; Wien: Peter Lang, 2001. 485 S. (Studien zur Deutschen und Europäischen Literatur des 19. und 20. Jahrhunderts; 45) ISBN 3-631-38276-6

\section{Gerlach, Christian; Aly, Götz}

Das letzte Kapitel. Realpolitik, Ideologie und der Mord an den ungarischen Juden 1944/ 45. Stuttgart; Zürich: Deutsche Verlags-Anstalt, 2002. - 481 S. ISBN 3-421-05505-X

dass. Frankfurt a. M.: Fischer, 2004. - 481 S. (Fischer Geschichte; 15772) ISBN 3-59615772-2

\section{Göllner, Ralf Thomas}

Die Europapolitik Ungarns von 1990 bis 1994. Westintegration, mitteleuropäische regionale Kooperation und Minderheitenfrage. München: Ungarisches Institut, 2001. - 334 S. (Studia Hungarica; 47) ISBN 3-929906-56-2

\section{[Gombás, István]}

Könige und Königinnen von Ungarn. Fürsten von Siebenbürgen. [Deutsche Übersetzung von Tamás Szántó]. [Budapest]: Corvina, 2000. - 32 S. ISBN 963-13-4844-X

\section{Haber, Peter; Petry, Erik; Wildmann, Daniel}

Jüdische Identität und Nation. Fallbeispiele aus Mitteleuropa. Köln: Böhlau Verlag, 2005. - 184 S. ISBN 3-412-25605-6

\section{Haber, Peter}

Die Anfänge des Zionismus in Ungarn (1897- 1904). Köln; Weimar; Wien: Böhlau Verlag, 2001. - 196 S. (Lebenswelten osteuropäischer Juden; 8) ISBN 3-412-10001-3

\section{Häder, Sonja; Wiegmann, Ulrich (Hrsg.)}

"Am Rande des Bankrotts ..." Intellektuelle und Pädagogik in de Gesellschaftskrisen der Jahre 1953, 1956 und 1968 in der DDR, Ungarn und der CSSR. Baltmannsweiler: Schneider-Verlag Hohengehren, 2004. - 161 S. ISBN 3-89676-807-7 
Hambuch, Wendel (Hrsg.)

Unser gemeinsames Erbe. 1100 Jahre deutsch-ungarische christliche Beziehungen. Der Beitrag herausragender, charismatischer deutschstämmiger Kleriker und Laienchristen zum kirchlichen und geistigen Leben in Ungarn. Budapest: St.-Gerhards-Werk Ungarn, 2001. 883 S. ISBN 963-00-7592-X

Hárs, Endre; Müller-Funk, Wolfgang; Reber, Ursula; Ruther, Clemens (Hrsg.) Zentren, Peripherien und kollektive Identitäten in Österreich-Ungarn. Tübingen: A. Francke, 2005. - 250 S. (Kultur - Herrschaft - Differenz; 9) ISBN 3-7720-8133-9

\section{Haus der Geschichte Baden-Württemberg;}

Kulturinstitut der Republik Ungarn (Hrsg.)

Ungarn und Deutschland - eine besondere Beziehung. Tübingen: Silberburg-Verlag, 2002.

- 226 S. ISBN 3-87407-521-4

\section{Hauszmann, János}

Ungarn. Vom Mittelalter bis zur Gegenwart. Regensburg: Friedrich Pustet, 2004. - 312 S. (Ost- und Südosteuropa) ISBN 3-7917-1908-4

\section{Hegedüs, András B.; Wilke, Manfred (Hrsg.)}

Satelliten nach Stalins Tod. Der "Neue Kurs". 17. Juni 1953 in der DDR. Ungarische Revolution 1956. Berlin: Akademie-Verlag, 2000. - 316 S. (Studien des Forschungsverbundes SED-Staat an der FU Berlin) ISBN 3-05-003541-2

\section{Hegedüs, Géza}

Ungarische Jahrhunderte. Ein kulturhistorischer Streifzug. Aus dem Ungarischen von Edit Baranyai und Mátyás Esterházy. Berlin: edition q, 1999. - 381 S. ISBN 3-86124-511-6

Horn, I. E. [d. i. Ignatz Einhorn]

Die Revolution und die Juden in Ungarn. Bevorwortet von Julius Fürst. Nachwort von Ambrus Miskolczy unter Mitwirkung von Michael K. Silber. Budapest: Universitas, 2001. - 189 S. (Europa varietas) ISBN 963-9104-51-5

\section{Hörner, Petra}

Hus - Hussiten. Dokumentation literarischer Facetten im 19. und 20. Jahrhundert. Frankfurt a. M.; Berlin; Bern; Bruxelles; New York; Oxford; Wien: Peter Lang, 2002. - 345 S. ISBN 3-631-38973-6 


\section{Horváth, István}

Die Sonne ging in Ungarn auf. Erinnerungen an eine besondere Freundschaft. Mit einer historischen Einführung von István Németh und einem Vorwort von Gyula Horn. [Aus dem Ungarischen von Péter Máté und György Józsa]. München: Universitas, 2000. - 391 S. ISBN 3-8004-1396-5 EST: ... és a falak leomlanak

\section{Hütt, Götz}

Das Außenkommando des KZ Buchenwald in Duderstadt. Ungarische Jüdinnen im Rüstungsbetrieb Polte. Norderstedt: Books on Demand GmbH, 2005. - 132 S. (Schriftenreihe der Geschichtswerkstatt Duderstadt) ISBN 3-8334-2646-2

\section{Kadlec, Markus (Hrsg.)}

Revolutionen nach 1945. [Jugoslawien 1946, China 1949, Ungarn 1956 ...] 2. Auflage. Wien: AGM, 2001. - 373 S. (Marxismus; 13) ISBN 3-901831-09-6

\section{Kaldori, Julia}

Jüdisches Budapest / Jewish Budapest. Ein Stadtführer. Vorwort von György Dalos. Wien: Verlag Mandelbaum Michael Baiculescu, 2004. - 272 S. ISBN 3-85476-111-2

\section{Kasza, Péter}

1954 - Fußball spielt Geschichte. Das Wunder von Bern. Bonn: Bundeszentrale für Politische Bildung, 2004. - 223 S. (Schriftenreihe / Bundeszentrale für Politische Bildung; 435) ISBN 3-89331-522-5

dass. Berlin; Brandenburg: be.bra-Verlag, 2004. - 224 S. ISBN 3-89809-046-9

dass. Frankfurt a. M.; Wien; Zürich: Büchergilde Gutenberg, 2004. - 223 S. ISBN 3-7632-5466-8

\section{Kerekes, Amália; Millner, Alexandra; Plener, Peter; Rásky, Béla (Hrsg.)}

Leitha und Lethe. Symbolische Räume und Zeiten in der Kultur Österreich-Ungarns. Tübingen; Basel: Francke, 2004. - VIII, 297 S. (Kultur - Herrschaft - Differenz; 6) ISBN 3-77208063-4

\section{Kéri, Heinrich}

Franken und Schwaben in Ungarn. Aufsätze zur Geschichte und Siedlungsgeschichte der Tolnau und der Oberen Baranya. Budapest: VudAK, 2002. - 291 S. (Neve-Zeitung-Bücher; 2) ISBN 963-00-2902-2 


\section{Klimó, Árpád von}

Nation, Konfession, Geschichte. Zur nationalen Geschichtskultur Ungarns im europäischen Kontext (1860-1948). München: R. Oldenbourg, 2003. - 453 S. (Südosteuropäische Arbeiten; 117) ISBN 3-486-56746-2

\section{Kochanowski, Jerzy (Hrsg.)}

Die "Volksdeutschen" in Polen, Frankreich, Ungarn und der Tschechoslowakei. Mythos und Realität. Osnabrück: Dr. Peter Fischer, 2004. (Einzelveröffentlichung des Deutschen Historischen Instituts Warschau; 12) ISBN 3-929759-84-5

\section{Körösi, Zsuzsanna; Molnár Adrienne}

Mit einem Geheimnis leben. Die Schicksale der Verurteilten von 1956. Aus dem Ungarischen von Tibor Schäfer. Herne: Gabriele Schäfer Verlag, 2005. - 269 S. (Studien zur Geschichte Ost- und Ostmitteleuropas; 4) ISBN 3-933337-35-6

\section{Krauss, Karl P.}

Deutsche Auswanderer in Ungarn. Ansiedlung in der Herrschaft Bóly im 18. Jahrhundert. Stuttgart: Franz Steiner Verlag, 2003. - 469 S. (Schriftenreihe des Instituts für donauschwäbische Geschichte und Landeskunde; 11) ISBN 3-515-08221-2

\section{Kristó, Gyula}

Die Geburt der ungarischen Nation. [Aus dem Ungarischen von Tibor Schäfer]. Herne: Gabriele Schäfer Verlag, 2000. - 199 S. (Studien zur Geschichte Ungarns; 4) ISBN 3933337-17-8 EST: A magyar nemzet megszületése

\section{Kühlmann, Wilhelm; Schindling, Anton (Hrsg.)}

Deutschland und Ungarn in ihren Bildungs- und Wissenschaftsbeziehungen während der Renaissance. [Arbeitsgespräch an der Herzog-August-Bibliothek in Wolfenbüttel, 24.26.09.2001, in Zusammenarbeit des "Wolfenbütteler Arbeitskreises für Renaissanceforschung" der Ungarischen Akademie der Wissenschaften, Budapest]. Stuttgart: Franz Steiner Verlag, 2004. - XII, 292 S. (Contubernium. Tübinger Beiträge zur UniversitätsWissenschaftsgeschichte; 62) ISBN 3-515-08551-3

\section{Leppin, Voker; Wien, Ulrich A. (Hrsg.)}

Konfessionsbildung und Konfessionskultur in Siebenbürgen in der Frühen Neuzeit. Stuttgart: Franz Steiner Verlag, 2005. - 236 S. (Quellen und Studien zur Geschichte des östlichen Europa; 66) ISBN 3-515-08617-X 


\section{Maner, Hans Christian; Schulze Wessel, Martin (Hrsg.)}

Religion im Nationalstaat zwischen den Weltkriegen 1918-1939. Polen - Tschechoslowakei - Ungarn - Rumänien. Stuttgart: Franz Steiner Verlag, 2002. - 219 S. (Forschungen zur Geschichte und Kultur des östlichen Mitteleuropa; 16) ISBN 3-515-08235-2

\section{Masát, András; Méhes, Márton; Rackebrandt, Wolfgang (Hrsg.)}

Raoul Wallenberg - Mensch in der Unmenschlichkeit. Ergebnisse der internationalen Forschung. Leipzig: Edition Kirchhof und Franke, 2002. - 187 S. (EKF Wissenschaft: Abteilung Zeitgeschichte; 1) ISBN 3-933816-14-9

\section{Mészáros, Tibor}

Doch die Seinen nahmen ihn nicht auf. Der Sekretär Kardinal Mindszentys erinnert sich. Aus dem Ungarischen von Christian Polzin. Herne: Gabriele Schäfer Verlag, 2002. 258 S. ISBN 3-933337-28-3 EST: Akit övéi be nem fogadtak

\section{Mihok, Brigitte (Hrsg.)}

Ungarn und der Holocaust. Kollaboration, Rettung und Trauma. Berlin: Metropol Verlag, 2005. - 175 S. (Dokumente, Texte, Materialien. Zentrum für Antisemitismusforschung der TU Berlin; 56) ISBN 3-936411-62-X

\section{Müller, Achim}

Zwischen Annäherung und Abgrenzung. Österreich-Ungarn und die Diskussion um Mitteleuropa im Ersten Weltkrieg. Marburg: Tectum-Verlag, 2001. - 412 S. ISBN 3-8288-8330-3

\section{Müller-Funk, Wolfgang; Plener, Peter; Ruthner, Clemens (Hrsg.)}

Kakanien revisited. Das Eigene und das Fremde (in) der österreichisch-ungarischen Monarchie. Tübingen; Basel: A. Francke, 2002. - VIII, 362 S. (Kultur - Herrschaft - Differenz; 1) ISBN 3-7720-3210-9

\section{Murber, llona}

Flucht in den Westen 1956. Ungarnflüchtlinge in Österreich (Vorarlberg) und Liechtenstein. Feldkirch: Rheticus-Gesellschaft, 2002. - 326 S. (Schriftenreihe der Rheticus-Gesellschaft; 41) ISBN 3-900866-74-0

\section{Németh, Balázs}

... Gott schläft nicht, er blinzelt uns zu ... Evangelisch-reformierte Lebensgestaltung zwischen Kontinuität und Wandel. Ungarn im 16. Jahrhundert als Beispiel. Frankfurt a. M.; Berlin; Bern; Bruxelles; New York; Oxford; Wien: Peter Lang Verlag, 2003. - 297 S. (Beiträge zur Volkskunde und Kulturanalyse; 3) ISBN 3-631-50406-3 


\section{Olechowski-Hrdlicka, Karin}

Die gemeinsamen Angelegenheiten der Österreichisch-Ungarischen Monarchie. Vorgeschichte - Ausgleich 1867 - Staatsrechtliche Kontroversen. Frankfurt a. M.; Berlin; Bern; Bruxelles; New York; Oxford; Wien: Peter Lang Verlag, 2001. - 552 S. (Rechtshistorische Reihe; 232) ISBN 3-631-36974-3

\section{Oplatka, Andreas}

Graf Stephan Széchenyi. Der Mann, der Ungarn schuf. Wien: Zsolnay, 2004. - 528 S. ISBN 3-552-053117-4

\section{Ornstein, Anna}

Das Apfelgehäuse. Erinnerungen. Als junges Mädchen im Holocaust. Aus dem amerikanischen Englischen von Martin Gossmann. Gießen: Haland und Wirth im Psychosozial-Verlag, 2004. - 143 S. ISBN 3-89806-934-6

Versklavung und Befreiung. Jüdische Schicksale aus Ungarn als zeitgemäße Pessachgeschichten. Konstanz: Wolfgang Hartung-Gorre, 2001. - 118 S. ISBN 3-89649-714-6

\section{Osers, Jan}

Unter Hakenkreuz und Sowjetstern. Erlebnisse eines Verfolgten in zwei Diktaturen. Berlin: Metropol, 2005. - 175 S. (Bibliothek der Erinnerung; 15) ISBN 3-936411-67-0

\section{Papp, Sándor}

Die Verleihungs-, Bekräftigungs- und Vertragsurkunden der Osmanen für Ungarn und Siebenbürgen. Wien: Verlag der Österreichischen Akademie der Wissenschaften, 2003. - 407 S. (Schriften der Balkankommission. Österreichische Akademie der Wissenschaften, Philosophisch-Historische Klasse; 42) ISBN 3-7001-3155-0

\section{Pesendorfer, Franz; Ujváry, Gábor (Hrsg.)}

Wiener Impressionen - auf den Spuren ungarischer Geschichte in Wien. Bécsi impressziók. Wien: Verband Wiener Volksbildung, 2002. - 109 S. ISBN 3-900799-45-8

\section{Puttkamer, Joachim von}

Schulalltag und nationale Integration in Ungarn. Slowaken, Rumänen und Siebenbürger Sachsen in der Auseinandersetzung mit der ungarischen Staatsidee 1867-1914. München: R. Oldenbourg, 2003. - 531 S. (Südosteuropäische Arbeiten; 115) ISBN 3-486-56741-1 


\section{Rajk, Klára}

Den Kampfgeist nie verloren. Jüdische Schicksale in Ungarn 1910- 1999. Aus dem Englischen von Marie-Elisabeth Rehn. Herausgegeben von Erhard Roy Wiehn. Konstanz: Wolfgang Hartung-Gorre, 2000. - 74 S. ISBN 3-89649-545-3

Romsics, Ignác u.a. (Hrsg.)

Option Europa. Deutsche, polnische und ungarische Europapläne des 19. und (frühen) 20. Jahrhunderts. Göttingen: Vandenhoeck und Ruprecht, 2005. - 1088 S. 3 Bde. ISBN 3-525-36287-0

\section{Romsics, Ignác}

Der Friedensvertrag von Trianon. Aus dem Ungarischen übersetzt von Tibor Schäfer. Herne: Gabriele Schäfer Verlag, 2005. - 224 S. (Studien zur Geschichte Ungarns; 6) ISBN 3933337-36-4

\section{Schall, Gunter}

Der österreichisch-ungarische Dualismus als Integrationskonzept. Hamburg: J. Kovac, 2001. - 272 S. (Schriftenreihe Volkswirtschaftliche Forschungsergebnisse; 69) ISBN 3-8300$0430-3$

\section{Scheuch, Manfred}

Das größere Europa. Ungarn, Slowenien, Tschechien, Slowakei, Polen und die Baltischen Staaten in Geschichte und Gegenwart. Wien: Ch. Brandstätter, 2002. - 200 S. ISBN 385498-169-4

\section{Schlomo Graber, Schlajme}

Von Ungarn durch Auschwitz-Birkenau, Fünfeichen und Görlitz nach Israel. Jüdische Familiengeschichte 1859-2001. Konstanz: Hartung-Gorre-Verlag, 2005. - 141 S. ISBN 3-89649757-X

Schmidl, Erwin A. (Hrsg.)

Die Ungarnkrise 1956 und Österreich. [Eine Publikation der Landesverteidigungsakademie Wien]. Wien; Köln; Weimar: Böhlau Verlag, 2002. - 317 S. ISBN 3-205-77009-9

\section{Schmidt, Tilmann; Gunst, Péter (Hrsg.)}

Das Zeitalter König Sigmunds. In Ungarn und im Deutschen Reich. Debrecen: Universität, Institut für Geschichtswissenschaft, 2000. ISBN 963-472-451-5 


\section{Schmidt-Schweizer, Andreas}

Vom Reformsozialismus zur Systemtransformation in Ungarn. Politische Veränderungsbestrebungen innerhalb der Ungarischen Sozialistischen Arbeiterpartei (MSZMP) von 1986 bis 1989. Frankfurt a. M.; Berlin; Bern; Bruxelles; New York; Oxford; Wien: Peter Lang Verlag, 2000. - 495 S. (Europäische Hochschulschriften; 3: 875) ISBN 3-631-36841-0

\section{Schneider, Johann}

Der Hermannstädter Metropolit Andrei von Saguna. Reform und Erneverung der orthodoxen Kirche in Siebenbürgen und Ungarn 1848. Köln; Weimar; Wien: Böhlau Verlag, 2005. - 258 S. (Studia Transylvanica; 32) ISBN 3-412-13505-4

\section{Seewann, Gerhard; Spannenberger, Norbert (Hrsg.)}

Akten des Volksgerichtsprozesses gegen Franz A. Basch, Volksgruppenführer der Deutschen in Ungarn, Budapest 1945/46. Unter der Berücksichtigung der Arbeiten von Friedrich Spiegel-Schmidt und Loránt Tilkovszky. München: R. Oldenbourg, LXXXIV, 549 S. (Buchreihe der Südostdeutschen Historischen Kommission; 37) ISBN 3-486-56485-4

\section{Seewann, Gerhard}

Ungarndeutsche und Ethnopolitik. Ausgewählte Aufsätze. Herausgegeben von Magyarországi Németek Országos Önkormányzata. [Budapest]: Osiris, 2000. - 264 S. (Kisebbségek kelet-középeurópában; 4) ISBN 963-379-852-3

\section{Soros, Tivadar}

Maskerade. Die Memoiren eines Überlebenskünstlers. Aus dem Englischen von Holger Fliessbach. Vorwort von Paul und George Soros. Stuttgart; München: Deutsche Verlagsanstalt, 2003. - 317 S. ISBN 3-421-05496-7

dass. München: Deutscher Taschenbuch Verlag, 2005. - 320 S. (dtv Sachbuch; 34168) ISBN 3-423-34168-8

\section{Spannenberger, Norbert}

Der Volksbund der Deutschen in Ungarn 1938- 1945 unter Horthy und Hitler. München: R. Oldenbourg, 2002. - VIII, 472 S. (Schriften des Bundesinstituts für Kultur und Geschichte der Deutschen im östlichen Europa; 22)

dass. 2., verbesserte Auflage. München: R. Oldenbourg, 2005. - 511 S. ISBN 3486-57728-X 


\section{Szabó, Csaba}

Die katholische Kirche Ungarns und der Staat in den Jahren 1945 - 1965. München: Ungarisches Institut, 2003. - 215 S. (Studia Hungarica; 48) ISBN 3-929906-58-9

\section{Szegö, Johann}

Eine kurze Geschichte Ungarns. Ereignisse, Persönlichkeiten, Jahreszahlen. München: Ueberreuter, 2005. - 96 S. ISBN 3-8000-7118-5

Timmermann, Heiner; Kiss, László (Hrsg.)

Ungarn 1956: Reaktionen in Ost und West. Berlin: Duncker und Humblot, 2000. - $80 \mathrm{~S}$. (Dokumente und Schriften der Europäischen Akademie Otzemhausen; 91) ISBN 3-42810221-5

\section{Tóth, Ágnes}

Migrationen in Ungarn 1945 - 1948. Vertreibung der Ungarndeutschen, Binnenwanderungen und slowakisch-ungarischer Bevölkerungsaustausch. Mit einer Einführung "Zur ungarischen Geschichtsschreibung über die Vertreibung der Ungarndeutschen 1980-1996" von Gerhard Seewann. München: R. Oldenbourg, 2001. - 248 S. (Schriften des Bundesinstituts für Kultur und Geschichte der Deutschen im Östlichen Europa; 12) ISBN 3-48656445-5

Tóth, István György (Hrsg.)

Geschichte Ungarns. [Übersetzung Éva Zádor]. Budapest: Corvina; Osiris, 2005. - 805 S. ISBN 963-135268-4

\section{Ujváry, Gábor (Hrsg.)}

Chronik des wiederholten Neubeginns. 1867-2001. Deutsch-ungarische diplomatische Beziehungen. Aus dem Ungarischen übersetzt. Budapest: Corvina, 2001. - 164 S. ISBN 963-13-5146-7

\section{Varga, Ervin}

Requiem für Sternträger. Die Lebenserinnerungen eines ungarischen Juden bis zu seiner Befreiung 1945. Herausgegeben vom Bund gegen Anpassung. Mit einem Geleitwort von Bert Wallace. Freiburg [Breisgau]: Ahriman-Verlag, 2000. - 104 S. (Ketzerbriefe, Sonderheft; 95) ISBN 3-89484-225-3

\section{Varga, Gábor}

Ungarn und das Reich vom 10. bis zum 13. Jahrhundert. Das Herrscherhaus der Árpáden zwischen Auflehnung und Emanzipation. München: Ungarisches Institut, 2003. - 367 S. (Studia Hungarica; 49) ISBN 3-929906-59-7 


\section{Volkmer, Gerald}

Das Fürstentum Siebenbürgen 1541 -1691. Außenpolitik und völkerrechtliche Stellung. Heidelberg: Arbeitskreis für Siebenbürgische Landeskunde; Kronstadt: Aldus-Verlag, 2002.

- 242 S. (Veröffentlichungen von Studium Transylvanicum) ISBN 3-929848-31-7

Die Siebenbürgische Frage (1878 - 1900). Der Einfluss der rumänischen Nationalbewegung auf die Beziehungen zwischen Österreich-Ungarn und Rumänien. Köln; Weimar; Wien: Böhlau, VII, 390 S. (Studium Transylvanica; 31 ) ISBN 3-412-04704-X

\section{Weissgerber, Klaus}

Ungarns wirkliche Frühgeschichte. Árpád eroberte schon 600 das Karpatenbecken. Gräfelfing: Mantis Verlag, 2003. - 319 S. ISBN 3-928852-24-8

\section{Wien, Ulrich A.; Zach, Krista}

Humanismus in Ungarn und Siebenbürgen. Politik, Religion und Kunst im 16. Jahrhundert. Köln; Weimar; Wien: Böhlau Verlag, 2004. - 240 S. (Siebenbürgisches Archiv; 3: 37) ISBN 3-412-10504-X

\section{Wurster, Herbert W. (Hrsg.)}

Bayern - Ungarn Tausend Jahre. Aufsätze zur Bayerischen Landesausstellung 2001. Vorträge der Tagung "Bayern und Ungarn im Mittelalter und in der Frühen Neuzeit” in Passau vom 15. bis 18. Oktober 2000. Passau: Verlag Archiv des Bistums und Oberhausmuseum Passau; Regensburg: Pustet, 2001. - 205 S. ISBN 3-7917-1754-5 


\section{Archäologie}

\section{Mozsolics, Amália}

Bronzefunde aus Ungarn. Depotfundhorizonte Hajdúböszörmény, Románd und Bükkszentlászló. Bearbeitet von Emily Schalk. Kiel: Oetker-Voges, 2000. - 117, 127 S. (Prähistorische Archäologie in Südosteuropa; 17) ISBN 3-935305-00-1 


\section{Sprach- und Literaturwissenschaft}

\section{Balogh, András F.}

Eine Unterredung gegen die Türken. Zweisprachige kommentierte Edition der deutschen Flugschrift VD 16: T2239. Herausgegeben, ediert und mit einer einführenden Studie versehen von F. András Balogh. Budapest: Littera Nova, 2003. - 179 S. (Kronosz könyvek; 9) ISBN 963-921276-8

Literatur, Literaturvermittlung, Identität. Budapest: VudAK, 2005. - 143 S. (VudAK-Bücher: Reihe Literatur; 10) ISBN 963-8333-12-X

\section{Bárczi, Géza}

Geschichte der ungarischen Sprache. Aus dem Ungarischen übertragen von Albrecht Friedrich. Innsbruck: Universität Innsbruck Institut für Sprachen und Literaturen, 2001. 502 S. (Innsbrucker Beiträge zur Kulturwissenschaft; Sonderheft 110) ISBN 3-85124-202-5

\section{Bart, István}

Ungarn. Land und Leute. Ein kleines Konversationslexikon der ungarischen Alltagskultur. [Aus dem Ungarischen von Éva Zádor]. Budapest: Corvina, 2000. - 240 S. ISBN 96313-4937-3

\section{Bassola, Péter}

Wortstellung im Sprachvergleich. (Deutsch-Niederländisch-Polnisch-Ungarisch). Tübingen: Groos, 2001. - 161 S. (Deutsch im Kontrast; 20) ISBN 3-87276-854-9

\section{Bécsy, Tamás}

Ritus und Drama. Aus dem Ungarischen von Ruth Futaky. Herne: Gabriele Schäfer Verlag, 2001. - 153 S. (Studien zur Literaturwissenschaft; 1) ISBN 3-933337-26-7 EST: Rítus és dráma

\section{Behring, Eva (Hrsg.)}

Grundbegriffe und Autoren ostmitteleuropäischer Exilliteraturen 1945-1989. Ein Beitrag zur Systematisierung und Typologisierung. Stuttgart: Franz Steiner Verlag, 2004. - 747 S. (Forschung zur Geschichte und Kultur des östlichen Mitteleuropa; 20) ISBN 3-515-08389-8 
Biechele, Werner; Balogh, András F. (Hrsg.)

Wer mag wohl die junge, schwarzäugige Dame seyn? Zuordnungsfragen, Bewertungskriterien der deutsch(sprachig)en Literatur in Ostmittel- und Südosteuropa. Budapest: ELTE Germanistisches Institut, 2002. - 191 S. (Budapester Beiträge zur Germanistik; 41) ISBN 963-463-598-9

\section{Bitskey, István}

Konfessionen und literarische Gattungen der frühen Neuzeit in Ungarn. Beiträge zur mitteleuropäischen vergleichenden Kulturgeschichte. Frankfurt a. M.; Berlin; Bern; Bruxelles; New York; Oxford; Wien: Peter Lang, 1999. - 209 S. (Debrecener Studien zur Literatur; 4) ISBN 3-631-34543-7

\section{Boronkai, Szabolcs (Hrsg.)}

Deutschsprachige Literatur und Kultur im Raum Ödenburg/Sopron (1790 - 1900). Auswahl und Nachwort von Szabolcs Boronkai. Budapest: Germanistisches Institut der ELTE, 2002. - 563 S. (Deutschsprachige Texte aus Ungarn; 1)

\section{Bremer, Thomas (Hrsg.)}

Grenzen überschreiten. Beiträge zur deutsch-ungarischen Kulturwissenschaft. Halle an der Saale: János Stekovics Verlag, 2001. - 126 S. (Colloquium Halense; 2) ISBN 3-932863$81-X$

\section{Brenner, Koloman}

Plosive der deutschen Dialekte in West-Ungarn. Eine kontrastive akustische Analyse. Budapest: ELTE, Germanistisches Institut, 2004. - 164 S. (Budapester Beiträge zur Germanistik; 44) ISBN 963-463-699-3

\section{Breuer, Dieter; Tüskés, Gábor (Hrsg.)}

Das Ungarnbild in der deutschen Literatur der frühen Neuzeit. Der ungarische oder dacianische Simplicissimus im Kontext barocker Reiseerzählungen und Simpliziaden. Bern; Berlin; Bruxelles; Frankfurt a. M.; New York; Oxford; Wien: Peter Lang, 2005. - 409 S. (Beihefte zur Simpliana; 1) ISBN 3-03910-428-4

\section{Budeus, Iris (Hrsg.)}

Der Ungar feiert weinend / Sírva vigad a magyar. Ungarische Sprichwörter und Lebensweisheiten / Magyar közmondások és életbölcseségek. Zusammengestellt von Iris Budeus. Übersetzt von Imre Gyulay. Unna: Friedrichsborn-Verlag, 2004. - 95 S. ISBN 3-9807724$1-1$ 


\section{Dahlmann, Dittmar; Potthoff, Wilfried (Hrsg.)}

Mythen, Symbole und Rituale. Die Geschichtsmächtigkeit der Zeichen in Südosteuropa im 19. und 20. Jahrhundert. Frankfurt a. M.; Berlin; Bern; Bruxelles; New York; Oxford; Wien: Peter Lang, 2000. - VIII, 293 S. (Heidelberger Publikationen zur Slavistik: B, Literaturwissenschaftliche Reihe; 14) ISBN 3-631-35511-4

\section{Deltcheva-Kampf, Veronika}

Onomasiologisches Modell für eine kontrastiv-typologische Betrachtung des suffixalen und kompositionellen Wortbildungsbereichs. (Am Beispiel des Finnischen, Ungarischen und Russischen). Wiesbaden: Harrassowitz, 2000. - XVI, 379 S. (Veröffentlichungen der Societas Uralo-Altaica; 52) ISBN 3-447-04313-X

\section{Deminger, Szilvia}

Spracherhalt und Sprachverlust in einer Sprachinselsituation. Sprache und Identität bei der deutschen Minderheit in Ungarn. Frankfurt a. M.; Berlin; Bern; Bruxelles; New York; Oxford; Wien: Peter Lang, 2004. - X, 231 S. (Variolingua; 21) ISBN 3-631-52632-6

\section{Erb, Maria; Knipf, Elisabeth; Orosz, Magdolna; Tarnói, László (Hrsg.)} „und Thut ein Gnügen Seinem Ambt". Festschrift für Karl Manherz zum 60. Geburtstag. Budapest: ELTE Germanistisches Institut, 2002. - 566 S. (Budapester Beiträge zur Germanistik; 39) ISBN 963-463-554-7

\section{Fassel, Horst (Hrsg.)}

Hugo Meltzl und die Anfänge der Komparatistik. Stuttgart: Franz Steiner Verlag, 2005. 194 S. (Materialien des Instituts für donauschwäbische Geschichte und Landeskunde Tübingen; 16) ISBN 3-515-08682-X

Pannonien vermessen. Ungarnbilder in der deutschen Literatur von Ekkehard IV. bis Siegfried Lenz. Stuttgart: Ungarisches Kulturinstitut Stuttgart; Institut für donauschwäbische Geschichte und Landeskunde Tübingen, 2004. - 423 S. (Miteinander; 2) ISSN 1611-5600

\section{Fassel, Horst; Balogh, András F.; Szabó, Dezső (Hrsg.)}

Zwischen Utopie und Realität. Deutsch-ungarische Literaturbeziehungen im Wandel. Budapest: ELTE Germanistisches Institut, 2001. - 225 S. (Budapester Beiträge zur Germanistik; 36) ISBN 963-463-449-4

\section{Finger, Zuzana}

Die slowakisch-ungarische Kommunikationsgemeinschaft. Eine Fallstudie. Wiesbaden: Otto Harrassowitz, 2000. - 188 S. (Balkanologische Veröffentlichungen; 35) ISBN 3-44704295-8 


\section{Fitz, Jenö; Mocsy, András; Soproni, Sándor}

Die römischen Inschriften Ungarns (RIU).

Lfg. 6: Das Territorium von Aquincum - Die civitas Eraviscorum und die Limesstrecke Matrica-Annamatia und das Territorium von Gorsium. Aus dem Ungarischen von Ursula Jakvary. Budapest: Enciklopédia Kiadó; Bonn: R. Habelt, 2001. - $470 \mathrm{~S}$. ISBN 3-7749-3054-6

\section{Forgács, Tamás}

Ungarische Grammatik. Wien: Edition Praesens, 2001. - 456 S. ISBN 3-7069-0107

dass. 2., verbesserte Auflage. Wien: Edition Praesens, 2004. - 454 S. ISBN 37069-0253-2

\section{Fried, István (Hrsg.)}

Österreichisch-ungarisch-mitteleuropäische literarisch-kulturelle Begegnungen. Szeged: Lehrstuhl für Vergleichende Literaturwissenschaft an der Philosophischen Fakultät der Universität, 2003. - 122 S. ISBN 963-482-650-4

\section{Gábor, lldikó (Hrsg.)}

Bibliotheca Nationis Hungariae. Der Katalog aus dem Jahr 1755. Textausgabe der Handschrift der Széchényi Nationalbibliothek Budapest. Catalogus librorum, dissertationum et manuscriptorum variorum ad rem Hungaricam praecipue facientium ex bibliotheca, quae Vitebergae est, Hungarorum congestus ab Adamo Latsny Turotzensi; Vitebergae Saxonum die XV. Nov. A.R.S.M.DCC.LV. Die ungarische Nationalbibliothek in der Universitäts- und Landesbibliothek Sachsen-Anhalt in Halle. Mit Beiträgen von István Monok und Dorothea Sommer. Hildesheim; Zürich; New York: Olms, 2005. - 272 S. ISBN 3-487-13002-5

\section{Gerner, Zsuzsanna}

Sprache und Identität in Nadasch/Mecseknádaschd. Eine empirische Untersuchung zur Sprachkontaktsituation und Identitätsbildung in der ungarndeutschen Gemeinde Nadasch. Budapest: ELTE Germanistisches Institut, 2003. - 170 S. (Ungarndeutsches Archiv; 7) ISBN 963-463-666-7

\section{Hanser, Eva M.}

Kleines Jagdwörterbuch. Kis vadászszótár. Deutsch - Ungarisch / Ungarisch - Deutsch. Die 500 wichtigsten Wörter. Wien: Eigenverlag Eva Hanser, 2001. - 84 S. ISBN 39501423-0-4 
Hárs, Endre (Hrsg.)

Verflechtungsfiguren. Intertextualität und Intermedialität in der Kultur Österreich-Ungarns. Frankfurt a. M.; Berlin; Bern; Bruxelles; New York; Oxford: Peter Lang, 2003. - 240 S. (Budapester Studien zur Literaturwissenschaft; 3) ISBN 3-631-50878-6

\section{Kállai, Ernst}

Schriften in deutscher Sprache. 1926-1930. [Herausgegeben und mit einem Nachwort versehen von Monika Wucher]. Budapest: Argumentum Kiadó, 2003. - 297 S. (Összegyúitött írások; 4) ISBN 963-7381-74-0

\section{Kárpáti, Paul}

Magyar-német szólások / Redensarten Ungarisch-Deutsch. Budapest: Argumentum; Berlin: Oberbaumverlag, 2001. - 225 S. ISBN 3-933314-39-9

\section{Kerekes, Amália; Millner, Alexandra; Orosz, Magdolna; Teller, Katalin (Hrsg.) \\ Mehr oder Weininger. Eine Textoffensive aus Österreich/Ungarn. Wien: W. Braumüller, 2005. - VIII, 320 S. ISBN 3-7003-1526-0}

\section{Kindt, Tom; Teller, Katalin (Hrsg.)}

Narratologie interkulturell. Studien zu interkulturellen Konstellationen in der deutschsprachigen und ungarischen Literatur 1880-1930. Frankfurt a. M.; Berlin; Bern; Bruxelles; New York; Oxford; Wien: Peter Lang, 2005. - 231 S. (Budapester Studien zur Literaturwissenschaft; 6) ISBN 3-631-53367-5

\section{Klosterberg, Brigitte; Monok, István (Hrsg.)}

Die Hungarica-Sammlung der Franckeschen Stiftungen zu Halle. Teil 1: Porträts. Tübingen; Halle: Niemeyer; Franckesche Stiftungen, 2003. - XXX, 269 S. (Hallesche Quellenpublikationen und Repertorien; 7) ISBN 3-484-84107-9

\section{Kriegleder, Wynfrid; Seidler, Andrea; Tancer, Jozef (Hrsg.)}

Deutsche Sprache und Kultur im Raum Pressburg. Bremen: Edition Lumière, 2002. - 286 S. (Presse und Geschichte; 4) ISBN 3-934686-07-9

\section{Kulcsár-Szabó, Ernö; Lörincz, Csongor; Molnár, Tamás Gábor (Hrsg.)}

Spielarten der Sprache. Transgression des Medialen in der Literatur. Budapest: Osiris, 2004. - 461 S. ISBN 963-389-692-4 


\section{Kulcsár-Szabó, Ernö; Manherz, Karl; Orosz, Magdolna (Hrsg.)}

„das rechte Maß getroffen". Festschrift für László Tarnói zum 70. Geburtstag. Berlin: [Seminar für Hungarologie an der Humboldt-Universität zu Berlin], 2004. - 347 S. (Berliner Beiträge zur Hungarologie; 14) ISBN 963-463-714-0

\section{Kunzmann-Müller, Barbara; Zielinski, Monika (Hrsg.)}

Sprachwandel und Lexikographie. Beispiele aus slavischen Sprachen, dem Ungarischen und Albanischen. Frankfurt a. M.; Berlin; Bern; Bruxelles; New York; Oxford; Wien: Peter Lang Verlag, 2002. - 215 S. (Berliner slawistische Arbeiten; 18) ISBN 3-631-39268-0

\section{Landsmannschaft der Deutschen aus Ungarn;}

\section{Landesverband Baden-Württemberg e. V.; Stadt Gerlingen (Hrsg.)}

Städtische Kultur in Ungarn um 1800. Literatur, Theater, Presse und Musik in Pest, Ofen und anderen Zentren bürgerlicher Kultur. Kulturtagung, 27. Oktober 2001 in Gerlingen. [Stuttgart]: Landsmannschaft der Deutschen aus Ungarn; Landesverband Baden-Württemberg e. V.; Gerlingen: Stadt Gerlingen, 2001. - 48 S.

\section{Langanke, Ulrich (Hrsg.)}

"das gueth von alten Lern". Jugend-Festschrift für Karl Manherz zum 60. Geburtstag. Budapest: ELTE Germanistisches Institut, 2002. - 272 S. (Budapester Beiträge zur Germanistik; 40) ISBN 963-463-555-5

Lange, Tanja u.a. (Hrsg.)

Literatur und Kultur in Grenzräumen. Frankfurt a. M.; Berlin; Bern; Bruxelles; New York; Oxford; Wien: Peter Lang, 2002. - 159 S. (Budapester Studien zur Literaturwissenschaft; 2) ISBN 3-631-39902-2

\section{Loewy, Hanno}

Béla Balázs - Märchen, Ritual und Film. Berlin: Vorwerk 8, 2003. - 432 S. ISBN 3930916-53-3

\section{Maitz, Péter}

Sozialpsychologie des Sprachverhaltens. Der deutsch-ungarische Sprachkonflikt in der Habsburgermonarchie. Tübingen: M. Niemeyer, 2005. - VII, 227 S. (Germanistische Linguistik; 256) ISBN 3-484-31256-4

\section{Manherz, Karl; Wild, Katharina}

Ungarndeutsches Archiv. 3. Zur Sprache und Volkskultur der Ungarndeutschen. Lehrbuch zur Minderheitenkunde. Budapest: ELTE Germanistisches Institut, 2002. - 184 S. ISBN 963-463-573 


\section{Maráz, Gabriella}

Sprachrettung oder Sprachverrat. Zur Normdiskussion in Bezug auf das Ungarische. Hamburg: J. Kovac, 2003. - 551 S. (Schriftenreihe Philologia; 58) ISBN 3-8300-1111-3

\section{Mátai, Mária D.}

Kleine ungarische Sprachgeschichte. Aus dem Ungarischen übersetzt von Albrecht Friedrich. Unter Mitarbeit von Ruth Futaky. Hamburg: Buske, 2002. - IX, 86 S. ISBN 3-87548-323-5

\section{Muhr, Rudolf (Hrsg.)}

Sprachen und Sprachkontakte im pannonischen Raum. Das Burgenland und Westungarn als mehrsprachiges Gebiet. Frankfurt a. M.; Berlin; Bern; Bruxelles; New York; Oxford: Peter Lang, 2005. - 242 S. (Österreichisches Deutsch; 5) ISBN 3-631-53511-2

\section{Nagy, Ilona; Lammel, Annamaria}

Die ungarische Bauernbibel. Wo Volkstümliches und Märchenhaftes auf die Bibel trifft. Aus dem Ungarischen übersetzt von Hans Skirecki. Mit einem Nachwort von Lutz Röhrich. Berlin: Kulturverlag Kadmos, 2001. - XI, 260 S. ISBN 3-931659-15-1

Wie Adam den Apfel verschluckte. Bauerbibel. Aus dem Ungarischen übersetzł von Hans Skirecki. Mit einem Nachwort von Lutz Röhrich. Berlin: Kulturverlag Kadmos, 2003. - XI, 260 S. ISBN 3-931659-21-6 EST: Parasztbiblia

\section{Németh, Attila (Hrsg.)}

Linguistische Beiträge ungarischer Nachwuchsgermanisten. Referate der I. Linguistischen Tagung ungarischer Nachwuchsgermanisten an der Universität Veszprém vom 28.-29. März 2003. Veszprém: Universitäts-Verlag; Wien: Edition Praesens, 2003. - 211 S. (Studia Germanica Universitatis Vesprimiensis: Supplement; 3) ISBN 3-7069-0255-9

\section{Nun, Katalin}

Mädchenleben in Ost und West - DDR, Ungarn, Bundesrepublik Deutschland. Gesellschaftlicher Wandel im Hohlspiegel ausgewählter Mädchenbücher aus drei Ländern. Frankfurt a. M.; Berlin; Bern; Bruxelles; New York; Oxford; Wien: Peter Lang, 2001. - 273 S. (Kinder- und Jugendkultur, -literatur und -medien. Theorie, Geschichte, Didaktik; 13) ISBN 3-631-37598-0

\section{Orosz, Magdolna; Schönert, Jörg (Hrsg.)}

Narratologie interkulturell. Entwicklungen - Theorien. Frankfurt A. M.; Berlin; Bern; Bruxelles; New York; Oxford; Wien: Peter Lang, 2004. - 207 S. (Budapester Studien zur Literaturwissenschaft; 5) ISBN 3-631-52204-5 


\section{Péteri, Attila}

Abtönungspartikeln im deutsch-ungarischen Sprachvergleich. Árnyaló partikulák németmagyar összehasonlításban. Budapest: ELTE Bölcsészettudományi Kara Dokłori Tanácsa, 2002. - 279 S. (Asteriskos; 5) ISBN 963-463-569-5

\section{Rieken, Bernd}

Wie die Schwaben nach Szulok kamen. Erzählforschung in einem ungarndeutschen Dorf. Mit einem Nachwort von Károly Gaál. Frankfurt a. M.; New York: Campus, 2000. 247 S. (Campus: Forschung; 808) ISBN 3-593-36481

\section{Sáfár, Éva}

Persuasive Texte. Eine vergleichende Untersuchung sprachlicher Argumentationsstrategien. Frankfurt a. M.; Berlin; Bern; Bruxelles; New York; Oxford; Wien: Peter Lang, 2001. 200 S. (Metalinguistica; 8) ISBN 3-631-36756-2

\section{Schubert, Gabriella; Dahmen, Wolfgang (Hrsg.)}

Bilder vom Eigenen und Fremden aus dem Donau-Balkan-Raum. Analysen literarischer und anderer Texte. München: Südosteuropa-Gesellschaft, 2003. - 370 S. (SüdosteuropaStudien; 71) ISBN 3-925450-95-5

\section{Schweikert, Werner (Hrsg.)}

Bibliographie der ungarischen Literatur des 20. Jahrhunderts in deutscher Sprache. Flein bei Heilbronn: Verlag Werner Schweikert, 2000. - X, 1019 S. ISBN 3-933696-01-1

\section{Szegedy-Maszák, Mihály; Scheibner, Tamás (Hrsg.)}

Der lange, dunkle Schatten. Studien zum Werk von Imre Kertész. Wien: Passagen; Budapest: Kortina Kiadó, 2004. - 376 S. ISBN 3-85165-654-7

\section{Szigeti, Imre}

Junge Germanisten aus Ungarn stellen sich vor. Frankfurt a. M., Berlin; Bern; Bruxelles; New York; Oxford; Wien: Peter Lang Verlag, 2005. - 258 S. ISBN 3-631-52376-9

Nominalisierungen und Argumentvererbung im Deutschen und Ungarischen. Tübingen: M. Niemeyer, 2002. - VIII, 215 S. (Linguistische Arbeiten; 449) ISBN 3-484-30449-9

\section{Tarnói, László}

Literatur und Kultur im Königreich Ungarn um 1800 im Spiegel deutschsprachiger Prosatexte. Auswahl und Nachwort von László Tarnói. Budapest: Argumentum Kiadó, 2000. 672 S. (Deutschsprachige Texte aus Ungarn; 3) ISBN 963-446-148-4 


\section{Tátrai Infanger, Nóra}

Der Sprachgebrauch der Ungarn in der Schweiz. Methoden zur Untersuchung der Mehrsprachigkeit. Frankfurt a. M.; Berlin; Bern; Bruxelles; New York; Oxford; Wien: Peter Lang Verlag, 2003. - XIV, 507 S. (Cross-Cultural Communications; 9) ISBN 3-631-39933-2

\section{Terrance, Albrecht; V. Szabó, László (Hrsg.)}

Kreuzwege der Literatur. Beiträge zum Symposium Ungarischer Nachwuchsgermanisten an der Universität Veszprém vom 27.-28. September 2002. Veszprém: Universitätsverlag; Wien: Edition Präsens, 2003. - 252 S. (Studia Germanica Universitatis Vesprimiensis: Supplement; 2) ISBN 3-7069-0254-0

\section{Tóth, József}

Worffeldforschung. Entwicklungsgeschichte und kontrastive semantische Untersuchungen. Szombathely: Lehrstuhl für Deutsche Sprache und Literatur der Pädagogischen Hochschule "Dániel Berzsenyi", 2001. - 219 S. (Acta germanistica Savariensia; 6)

\section{Tressel, Anton}

Ungarische Familiennamen im deutschen Sprachgebiet. [Erklärung der ungarischen und ungarisch geschriebenen deutschen und slawischen Familiennamen im deutschen Sprachgebiet]. Bous: A. Tressel, 2002. - 312 S. ISBN 3-930771-18-7

\section{Tüskés, Gábor}

Johannes Nádasi. Europäische Verbindungen der geistlichen Erzählliteratur Ungarns im 17. Jahrhundert. Tübingen: M. Niemeyer, 2001. - X, 533 S. (Frühe Neuzeit; 62) ISBN 3484-36562-5

Wallas, Armin u.a. (Hrsg.)

Jüdische Identitäten in Mitteleuropa. Literarische Modelle der Identitätskonstruktion. Tübingen: M. Niemeyer, 2002. - VI, 325 S. (Condition Judaica; 38) ISBN 3-484-65138-5

\section{Wernitzer, Julianna}

Dynamische Orte der Intertextualität in der ungarischen Gegenwartsprosa. Frankfurt a. M.; Berlin; Bern; Bruxelles; New York; Oxford; Wien: Peter Lang, 2003. - 193 S. (Europäische Hochschulschriften: Reihe 18, Vergleichende Literaturwissenschaft; 106) ISBN 3-631-50281-8

\section{Wild, Katharina}

Zur komplexen Analyse der "Fuldaer" deutschen Mundart Südungarns. Budapest: ELTE Germanistisches Institut, 2003. - 167 S. (Ungarndeutsches Archiv; 6) ISBN 963-463668-3 
Winfried, Ulrich (Hrsg.)

Deutsch in Estland und Ungarn. Beiträge zur Germanistik und Fachdidaktik. Frankfurt a. M.; Berlin; Bern; Bruxelles; New York; Oxford; Wien: Peter Lang Verlag, 2001. - 154 S. (Folia Didactica; 6) ISBN 3-631-37985-4

\section{Zarbach-Peter, Timea}

Verb und Valenz. Kontrastive Untersuchungen der ungarischen und der deutschen Gegenwartssprache unter valenztheoretischem Aspekt. Taunusstein: Dr. H. Driesen, 2005. - 376 S. (Driesen Edition Wissenschaft) ISBN 3-936328-44-7 


\section{Theater, Film, Musik}

\section{Balázs, Béla}

Der Geist des Films. Mit einem Nachwort von Hanno Loewy. Frankfurt a. M.: Suhrkamp Verlag, 2001. - 237 S. (stw; 1537) ISBN 3-518-29137-8

Der sichtbare Mensch oder die Kultur des Films. Mit einem Nachwort von Helmut H. Diederichs. Frankfurt a. M.: Suhrkamp Verlag, 2001. - 177 S. (stw; 1536) ISBN 3-51829136-X

\section{Gulyás, Réka}

Von der Puszta will ich träumen... Das Ungarn-Bild im deutschen Spielfilm 1929-1939. Innsbruck: Universität Innsbruck Institut für Sprachen und Literaturen, 2000. - 155 S. (Innsbrucker Beiträge zur Kulturwissenschaft; Sonderh. 107) ISBN 3-85124-196-7 


\section{Sozialwissenschaften, Soziologie}

\section{Amt der Burgenländischen Landesregierung (Hrsg.)}

Kirche, Staat und Gesellschaft im pannonischen Raum. Volksfrömmigkeit, Bildungs- und Sozialwesen. Eisenstadt: Amt der Burgenländischen Landesregierung, 2002. - $173 \mathrm{~S}$. (Internationales Kulturhistorisches Symposium Mogersdorf; 30) ISBN 3-901517-38-3

\section{Andorka, Rudolf}

Einführung in die soziologische Gesellschaftsanalyse. Ein Studienbuch zur ungarischen Gesellschaft im europäischen Vergleich. Opladen: Leske und Budrich, 2001. - 558 S. ISBN 3-8100-2548-8

\section{Baierlein, Jochen}

Gesundheitsstatus und Gesundheitssystem in Deutschland und Ungarn. Ungarn auf dem Weg in die Europäische Union. [Elektronische Ressource]. Würzburg, 2005. urn:nbn:de:bvb:20opus- 15985

\section{Belinszki, Eszter}

Zwischen Gleichheitsnorm und Differenzerfahrung. Geschlechterkonstruktionen ungarischer Journalistinnen. [Elektronische Ressource]. Bochum, 2003. urn:nbn:de:hbz:294-9654

\section{Brenner, Christiane; Heumos, Peter (Hrsg.)}

Sozialgeschichtliche Kommunismusforschung. Tschechoslowakei, Polen, Ungarn und DDR 1948 - 1968. Vorträge der Tagung des Collegium Carolinum in Bad Wiessee vom 22. bis 24. November 2002. München: R. Oldenbourg, 2005. - 558 S. (Bad Wiesseer Tagungen des Collegium Carolinum; 27) ISBN 3-486-57696-8

\section{Haumersen, Petra; Rademacher, Helmolt; Ropers, Norbert}

Konfliktbearbeitung in der Zivilgesellschaft. Die Workshop-Methode im rumänisch-ungarischen Konflikt. Münster, Hamburg, London: LIT, 2002. - 191 S. (Konflikttransformation; 1) ISBN 3-8258-5465-5

\section{Heindl, Waltraud; Király, Edit; Millner, Alexandra (Hrsg.)}

Fravenbilder, feministische Praxis und nationales Bewusstsein in Österreich-Ungarn 1867 1914. Tübingen: A. Francke, 2005. - 200 S. (Kultur - Herrschaft - Differenz; 8) ISBN 37720-8131-2 
Heindl, Waltraud; Litván, György; Malfér, Stefan; Somogyi, Éva (Hrsg.)

Eliten und Außenseiter in Österreich und Ungarn. Wien; Köln; Weimar: Böhlau Verlag, 2001. 139 S. (Begegnungen an der Donau) ISBN 3-205-99344-6

\section{Járosi, Katalin}

Ethnizität, Grossstadt, Repräsentation. Strategien ethnischer Identitätsbildung bei in Berlin lebenden Ungarinnen und Ungarn. Münster u.a.: Waxmann Verlag, 2002. - 185 S. (Internationale Hochschulschriften; 383) ISBN 3-8309-1192-0

Minutillo, Agnes (Hrsg.)

Frauen-Chronik aus Ungarn. 1940- 1990. Graz: Styria, 1998. - 111 S. ISBN 3-901921-00-1

\section{Papp, Claudia}

"Die Kraft der weiblichen Seele". Feminismus in Ungarn, 1918- 1941. Münster: LIT Verlag, 2004. - 555 S. (Schriftenreihe der Stipendiatinnen und Stipendiaten der Friedrich-EbertStiftung; 25) ISBN 3-8258-7472-9

\section{Reif, Elisabeth; Schwarz, Ingrid (Hrsg.)}

Zwischen Ausgrenzung und Integration. Ein interdisziplinäres Friedensprojekt zum Thema "Interkulturelle Kommunikation mit Ungarn". Wien: Mandelbaum, 2004. - 283 S. (Edition Südwind) ISBN 3-85476-119-8

\section{Tomcsányi, Teodóra}

Gesellschaft und seelische Gesundheit. Mentalhygiene in Theorie, Forschung, Praxis und Ausbildung. Übersetzung aus dem Ungarischen von Angelika Balog. Freiburg im Breisgau: Lambertus, 2003. - 271 S. ISBN 3-7841-1476-8 


\section{Ethnologie}

\section{Großmann, Georg Ulrich (Hrsg.)}

Hausbau und Bauforschung in Ungarn. Bericht über die Tagung des Arbeitskreises für Hausforschung in Székesfehérvár vom 19.-23.06.1996. Marburg: Jonas Verlag für Kunst und Literatur, 2004. - 352 S. (Jahrbuch für Hausforschung; 47) ISBN 3-89445-292-7

\section{Liszka, József}

Volkskunde der Ungarn in der Slowakei. Zwischen Karpaten und der Ungarischen Tiefebene. Passau: Lehrstuhl für Volkskunde an der Universität Passau, 2003. - 505 S. (Passaver Studien zur Volkskunde; 22)

\section{Ruff, Gabriella}

Praktiken und Inszenierungen in der ungarischen Begräbniskultur von 1940 bis 2002. Am Beispiel der Gemeinde Moor. Tübingen: Univ., Diss., 2003. - VIII, 274 S.

\section{Schumacher, Monika (Hrsg.)}

Cifraszür, Hirtenmantel. Vom allıäglichen Kleidungsstück zum nationalen Symbol. Katalog zur Jahresausstellung 2003 des Ethnographischen Museum Schloß Kittsee 30. März bis 2. November 2003. Kittsee: Ethnographisches Museum, 2003. - 47 S. ISBN 3-902381$00-0$

\section{Tuntuzisz, Gabriella}

Hexenvorstellungen im ungarischen Volksglauben. Hamburg: J. Kovac, 2005. - 104 S. (Schriften zur Kulturwissenschaft; 61) ISBN 3-8300-1855-X 


\section{Psychologie}

\section{Mérö, László}

Die Grenzen der Vernunft. Kognition, Intuition und komplexes Denken. Deutsch von Anita Ehlers. Reinbek bei Hamburg: Rowohlt Taschenbuch Verlag, 2002. - 446 S. (rororo sachbuch science; 61489) ISBN 3-499-61419-7

Die Logik der Unvernunft. Spieltheorie und die Psychologie des Handelns. Deutsch von Anita Ehlers. Reinbek bei Hamburg: Rowohlt Taschenbuch Verlag, 2000. - 348 S. (rororo sachbuch science; 60821) ISBN 3-499-60821-9 


\section{Pädagogik}

\section{Erdélyi, Andrea}

Ungarische Heilpädagogik im Wandel. Entwicklung und Situation der Heilpädagogik in Ungarn angesichts des politischen Systemwandels unter besonderer Berücksichtigung der Geistigbehindertenpädagogik. Würzburg: Ergon-Verlag, 2002. - 487 S. (Erziehung, Schule, Gesellschaft; 25)

Lehmann, Ute (Hrsg.)

Aktuelle Tendenzen in der Weiterentwicklung der professionellen Ausbildung von Pädagogen/Lehrern im Rahmen der Bildungsreform der beteiligten Länder. Bildungsreform in der Folge politischer und gesellschaftlicher Transformationen in Belarus', Polen, Russland, Ungarn und den neuen Bundesländern Deutschlands. Materialien einer internationalen wissenschaftlichen Tagung des Instituts für Pädagogik der Universität Potsdam vom 16. bis 19. September 2002 im Pädagogischen Landesinstitut Ludwigsfelde-Struveshof. Potsdam: Universitätsverlag, 2003. - 179 S. ISBN 3-935024-77-0 


\section{Recht}

\section{Andová, Katarina}

Das Mobiliarpfandrecht in Österreich, Ungarn, Tschechien und der Slowakei. Unter besonderer Berücksichtigung des besitzlosen Pfandrechts. Wien: Manz, 2004. - XVIII, 333 S. (Schriften des österreichischen Notariats; 27) ISBN 3-214-08922-6

\section{Bauer, Bence}

Jogi szókincs. Die wichtigsten Fachausdrücke des ungarischen Rechts. Passau: RCDS, 2003.

- 84 S. ISBN 3-9805057-3-2

dass. Bonn: Passauer Publikationen, 2005. - 88 S. ISBN 3-9809241-5-7

\section{Baumgartner, Peter; Schinkowitz, Stefan}

Vermögensentzug bei Burgenländischen Kroaten und Ungarn. Wien; München: R. Oldenbourg, 2004. - 86 S. (Veröffentlichungen der Österreichischen Historikerkommission. Vermögensentzug während der NS-Zeit sowie Rückstellungen und Entschädigungen seit 1945 in Österreich; 23/4) ISBN 3-486-56796-9

\section{Berger, Johannes}

Minderheitenschutz in Ungarn. Die verfassungs- und verwaltungsrechtlichen Regelungen. Tübingen: Medien-Verlag Köhler, 2001. - III, 296 S. ISBN 3-935625-05-7

\section{Center of Legal Competence (Hrsg.)}

Unternehmer in Ungarn. Ausgewählte Rechtsfragen. Berlin: BWV Berliner WissenschaftsVerlag; Wien; Graz: Never Wissenschafts-Verlag, 2005. - 202 S. (Schriftenreihe des Center of Legal Competence; 20) ISBN 3-8305-1037-3

\section{Csöri, Andrea}

Entwicklung des ungarischen Zivilrechts. Münster (Westfalen): Universität, XVII, 183 S. 2002.

\section{Dietz, Adolf (Hrsg.)}

Urheberrecht in Mittel- und Osteuropa. Handbuch mit Einführungen und Rechtstexten.

Teil II: Estland, Lettland, Litauen, Tschechien, Ukraine, Ungarn. Berlin: BWV Berliner Wissenschafts-Verlag, 2002. - 604 S. ISBN 3-87061-742-X

\section{Djanani, Christiana; Brähler, Gernot; Ulbrich, Philipp}

Investitionen und Steuern in Ungarn. Doing Business in Hungary. Herne; Berlin: Neue Wirtschafts-Briefe, 2003. - XII, 186 S. ISBN 3-482-52491-2 


\section{Erdö, Péter}

Kirchenrecht im mittelalterlichen Ungarn. Gesammelte Studien. Berlin: Frank und Timme, 2005. - 238 S. (Aus Religion und Recht; 3) 3-86596-028-6

\section{Fenge, Anne}

Niedriglohn- und Hochlohnanbieter im Bausektor. Dargestellt am Beispiel der Bundesrepublik Deutschland und der Republik Ungarn. Lohmar: J. Eul, 2004. - XIX, 318 S. ISBN 3-89936264-0

\section{Gálffy, Zoltán}

Immobilienbesteverung nach dem EU-Beitritt. Slowakische Republik, Tschechische Republik, Ungarn. Berlin: Berliner Wissenschaftsverlag; Wien; Graz: Neuer Wissenschaftlicher Verlag, 2005. (Schriftenreihe des Center of Legal Competence; 15) ISBN 3-8305-1032-2

\section{Gyulai-Schmidt, Andrea}

Harmonisierung des ungarischen Gesellschaftsrechts mit dem Recht der Europäischen Union. Gründung und Kapitalschutz ungarischer Kapitalgesellschaften im Spannungsfeld zwischen Niederlassungsfreiheit und Gläubigerschutz. Baden-Baden: Nomos Verlags-Gesellschaft, 2004. - 420 S. (Schriftenreihe des Europa-Kollegs Hamburg zur Integrationsforschung; 40) ISBN 3-8329-0456-5

\section{Horn, Norbert (Hrsg.)}

Die Neugestaltung des Privatrechts in Mittelosteuropa und Osteuropa. Polen, Russland, Tschechien, Ungarn. München: Beck, 2002. - XII, 161 S. (Schriften des Rechtszentrums für Europäische und Internationale Zusammenarbeit (RIZ); 17) ISBN 3-406-49860-4

\section{Knaus, Michael; Wakounig, Marian Raimund (Hrsg.)}

Steuer- und Gesellschaftsrecht der EU-Beitrittsländer. Polen, Slowakei, Slowenien, Tschechien, Ungarn. Zürich: Schulthess, 2003. - 500 S. ISBN 3-406-51179-1

dass. 2. Auflage. München: Beck, 2004. - 500 S. ISBN 3-406-52226-2

\section{Kocsis, Imola}

Internationale Rechtsberatung durch die Europäische Union. Eine systematische Analyse der Unterstützung der Rechtsharmonisierung am Beispiel Ungarns. Baden-Baden: NomosVerlagsgesellschaft, 2004. - 217 S. (Nomos Universitätsschriften: Recht; 410) ISBN 38329-0571-5 


\section{Küpper, Herbert}

Justizreform in Ungarn. München: Forschungsverbund Ost- und Südosteuropa, 2004. 66 S. (Forost-Arbeitspapiere; 23) ISBN 3-9809264-7-8

\section{Louisoder, Tatjana}

Unternehmensbesteverung in Ungarn. Entwicklung eines Strategiekonzeptes für den deutschen Investor in Ungarn unter Berücksichtigung steuerlicher Wirkungen. Göttingen: Cuvillier, 2000. - XI, 222 S. ISBN 3-89712-677-X

\section{Pajor-Bytomski, Magdalena}

Gesellschaftsrecht in Ungarn: Eine Einführung mit vergleichenden Tabellen. Leiffaden. 2. Auflage. München: Rehm, 2001. - XVIII, 155 S. (Gesellschaftsrecht International) ISBN 38073-1576

\section{Pusill-Wachsmuth, Kirsten}

Der Typenvergleich zur Einordnung ausländischer Gesellschaften in das deutsche System der Einkommensbesteuerung. Zudem konkrete Einordnung der Gesellschaftsformen der Staaten Ungarn, Polen und Slowenien. Frankfurt a. M.; Berlin; Bern; Bruxelles; New York; Oxford; Wien: Peter Lang Verlag, 2003. - XLI, 264 S. (Europäische Hochschulschriften: Reihe 2, Rechtswissenschaft; 3796) ISBN 3-631-51711-4

\section{Roy, Friedemann}

Niederlassungsrecht und Kapitalverkehrsfreiheit in Polen, Tschechien und Ungarn. Die Auswirkungen der Europa-Abkommen auf die Tätigkeit der Kreditinstitute. Wiesbaden: Deutscher Universitäts-Verlag, 2002. - XIX, 344 S. ISBN 3-8344-0626-8

\section{Sander, Sven}

Die ungarische Gesellschaft mit beschränkter Haftung. Mit Gemeinsamkeiten zur deutschen GmbH. München: Sellier European Law Publishers, 2003. - XVIII, 188 S. ISBN 3935808-17-8

\section{Schmitz-Filvig, Ilona}

Die rechtlichen Rahmenbedingungen für ausländische Investitionen in Ungarn. Frankfurt a.M.; Berlin; Bern; Bruxelles; New York; Oxford; Wien: Peter Lang Verlag, 2001. - XXI, 251 S. (Europäische Hochschulschriften: Reihe 2, Rechtswissenschaft; 3244) ISBN 3-631-38430-0 


\section{Stolz, Armin; Wieser, Bernd (Hrsg.)}

Vergleichendes Verwaltungsrecht in Ostmitteleuropa. Grundriss der Verwaltungsordnungen Polen, Tschechiens, der Slowakei und Ungarns. Berlin: Berliner Wissenschaftsverlag; Wien: Verlag Österreich, 2004. - XLIX, 812 S. (Schriften zur Rechtsvergleichung im öffentlichen Recht; 1) ISBN 3-8305-0632-5

\section{Széchényi, Attila}

Das neve ungarische Strafprozessrecht im Spannungsverhältnis zwischen Rechtsstaatsprinzip, Verfahrensökonomie und Effizienz. Frankfurt a. M.; Berlin; Bern; Bruxelles; New York; Oxford; Wien: Peter Lang, 2003. - 135 S. (Studien des Instituts für Ostrecht München; 48) ISBN 3-631-51853-6

\section{Székessy, Lilia}

Gerechtigkeit und inklusiver Rechtspositivismus. Berlin: Duncker und Humblot, 2003. 175 S. (Münsterische Beiträge zur Rechtswissenschaft; 150) ISBN 3-428-11057-9

\section{Vékás, Lajos; Paschke, Marian (Hrsg.)}

Europäisches Recht im ungarischen Privat- und Wirtschaftsrecht. Münster: LIT, 2004. XXV, 544 S. (Deutsches und internationales Wirtschaftsrecht; 40) ISBN 3-8258-7433-8

\section{Vida, Alexander; Kowal-Wolk, Tatjana; Hegyi, Gábor}

Ungarisches Patentrecht. Köln; Berlin; Bonn; München: Heymann, 2001. - XXX, 331 S. (Schriftenreihe zum gewerblichen Rechtsschutz; 114) ISBN 3-452-24891-7

\section{Voigt, Katrin}

Der Schutz nationaler ungarischer Minderheiten durch ihren Ursprungsstaat aufgrund des ungarischen Statusgesetzes und dessen Vereinbarkeit mit dem Völkerrecht. Frankfurt a. M.; Berlin; Bern; Bruxelles; New York; Oxford; Wien: Peter Lang, 2005. - 413 S. (Europäische Hochschulschriften: Reihe 2, Rechtswissenschaft; 4260) ISBN 3-631-54452-9

\section{Zentai, Susanna}

Die strafrechtliche und die zivilrechtliche Aufklärung zu der Einwilligung in die ärztliche Heilbehandlung in einem Rechtsvergleich mit Ungarn. Trier: Universität, 2004. - XLIX, 326 S.

\section{Zsernaviczky, Peter}

Die Umsetzung der gewährleistungsrechtlichen Vorschriften der Verbrauchsgüterkaufrichtlinie in Ungarn und in England. [Als Manuskript gedruckt]. Berlin: dissertation.de, 2005. XXVI, $197 \mathrm{~S}$. 


\section{Politologie, Wirtschaft}

\section{Ágh, Attila}

Ungarn zwischen zentralistischer Mehrheitsdemokratie und europäischer Mehrebenendemokratie. Bonn: Friedrich-Ebert-Stiftung, 2002. - 19 S. (Politikinformation Osteuropa; 102)

\section{Bruha, Thomas; Schäfer, Wolf; Wass von Czege, Andreas (Hrsg.)}

Die Europäische Union nach der Erweiterung. Deutsche und ungarische Standpunkte. BadenBaden: Nomos Verlags-Gesellschaft, 2004. - 209 S. (Schriftenreihe des Europa-Kollegs Hamburg zur Integrationsforschung; 45) ISBN 3-8329-0951-6

\section{Bucerius, Angelika}

Die Rentensysteme in Polen und Ungarn. Herausforderungen durch den Transformationsprozess und den EU-Beitritt. Frankfurt a. M.; Berlin; Bern; Bruxelles; New York; Oxford; Wien: Peter Lang, 2005. - 468 S. (Europäische Hochschulschriften: Reihe 5, Volks- und Betriebswirtschaft; 3118) ISBN 3-631-52876-0

\section{Busek, Erhard (Hrsg.)}

Zentraleuropa-Almanach Ungarn. Daten, Fakten \& Informationen. Wissenswertes über Ungarn. Wien: Molden-Verlag, 2002. - 118 S. ISBN 3-85485-070-0

\section{Csoboth, István}

Mitwirkung der Bürger an der Demokratie in Ungarn. Verfassungsnorm und Verfassungswirklichkeit. Wiesbaden: Deutscher Universitäts-Verlag, 2003. - XIV, 145 S. ISBN 3-82444535-2

\section{Deppe, Rainer; Tatur, Melanie}

Rekonstitution und Marginalisierung. Transformationsprozesse und Gewerkschaften in Polen und Ungarn. Frankfurt a. M.; New York: Campus-Verlag, 2002. - 360 S. (Studienreihe des Instituts für Sozialforschung Frankfurt am Main) ISBN 3-593-37009-3

\section{Derianecz, Agnes}

Kulturelle Unterschiede in der deutsch-ungarischen Wirtschaftskommunikation. Göttingen: Cuvillier, 183 S. ISBN 3-89873-850-7 


\section{Dieringer, Jürgen}

Staatlichkeit im Wandel? Die Regulierung der Sektoren Verkehr, Telekommunikation und Energie im ungarischen Transformationsprozeß. Opladen: Leske und Budrich, 2001. 263 S. (Theorie und Praxis never Staatlichkeit; 2) ISBN 3-8100-2862-2

\section{Dömötörfi, Tibor}

Diktatur und soziale Anomie. Augsburg: Universität, 2002. - 215 S.

\section{Dreyhaupt von Speicher, Peggy}

Die Regionen Polens, Ungarns und Tschechischen Republik vor dem EU-Beitritt. Interregionale Disparitäten, Bestimmungsfaktoren und Lösungsansätze. Frankfurt a. M.; Berlin; Bern; Bruxelles; New York; Oxford; Wien: Peter Lang Verlag, 2002. - 308 S. (Schriften zur Wirtschaftstheorie und Wirtschaftspolitik; 24) ISBN 3-631-39691-0

\section{Franzen, Wolfgang; Haarland, Hans-Peter; Niessen, Hans-Joachim (Hrsg.)}

Osteuropa zwischen Euphorie, Enttäuschung und Realität. Daten zur Systemtransformation 1990-2003 für eine nachhaltige Entwicklung. Frankfurt a. M.; New York: Campus-Verlag, 2005. - 225 S. (Schriftenreihe der Forschungsstelle für Empirische Sozialökonomik e.V.) ISBN 3-593-37700-4

\section{Gorzka, Gabriele (Hrsg.)}

Transformation der Wissenschaften in Mittel- und Osteuropa. Polen, Rumänien, Russland, Slowakei, Tschechien, Ungarn. Kassel: Kassel Univ. Press, 2003. - 222 S. (Ost-West-Dialog; 6) ISBN 3-89958-011-7

\section{Grotz, Florian}

Politische Institutionen und post-sozialistische Parteiensysteme in Ostmitteleuropa. Polen, Ungarn, Tschechien und die Slowakei im Vergleich. Opladen: Leske und Budrich, 2000. 496 S. (Junge Demokratien; 5) ISBN 3-8100-2746-4

\section{Günther, Jutta}

Das Zustandekommen von Technologie-Spillovers durch ausländische Direktinvestitionen. Eine empirische Untersuchung am Beispiel der ungarischen Industrie. Baden-Baden: Nomos Verlags-Gesellschaft, 2003. - $182 \mathrm{~S}$. (Schriften des Instituts für Wirtschaftsforschung Halle; 14) ISBN 3-8329-0429-8

\section{Handrich, Lars}

Externe Unternehmensfinanzierungen und Institutionen der Finanzsysteme. Eine vergleichende Untersuchung der Entwicklung in Ungarn und der Tschechischen Republik. Aachen: Shaker, 2004. - 201 S. (Berichte aus der Volkswirtschaft) ISBN 3-8322-2646-X 


\section{Hrbek, Rudolf (Hrsg.)}

Die Osterweiterung der EU. Problemfelder und Lösungsansätze aus deutscher und ungarischer Sicht. Beiträge zu einer Tagung des Staatsministeriums Baden-Württemberg in Zusammenarbeit mit dem Europäischen Zentrum für Förderalismus-Forschung Tübingen. Tübingen: Eberhard-Karls-Universität, Europäisches Zentrum für Förderalismus-Forschung, 2000. 185 S. (Occasional Papers; 22) ISBN 3-9806978-0-0

\section{Kipke, Rüdiger}

Das Politische System Ungarn. Eine Einführung. Wiesbaden: VS Verlag für Sozialwissenschaften, 2005. - 154 S. ISBN 3-531-13603-8

\section{Knogler, Michael; Vincentz, Volkhart}

Szenarien der mittelfristigen Konvergenz der EU-Beitrittsländer Polen, Slowakische Republik und Ungarn. Gutachten. Erstellt im Auftrag des Bundesministeriums der Finanzen. München: Osteuropa-Institut, 2003. - XVI, 125 S. (Arbeiten aus dem Osteuropa-Institut München; 244) ISBN 3-9211396-81-6

\section{Krossa, Anne Sophie}

Kollektive Identitäten in Ostmitteleuropa. Polen, Tschechien und Ungarn und die Integration der Europäischen Union. Berlin: wvb Wissenschaftlicher Verlag Berlin, 2005. - XXX, $210 \mathrm{~S}$.

\section{Küpper, Herbert}

Autonomie im Einheitsstaat. Geschichte und Gegenwart der Selbstverwaltung in Ungarn. Berlin: Duncker und Humblot, 2002. - 532 S. (Schriftenreihe des Kommunikationswissenschaftlichen Instituts der Universität Potsdam; 9) ISBN 3-428-10635-0

\section{Laschet, Armin; Pflüger, Friedbert (Hrsg.)}

Ungarn in Europa. Karlspreis 2001 an György Konrád. Aachen: Einhard-Verlag, 2001. 173 S. ISBN 3-930701-89-8

\section{Machos, Csilla}

Parteien in Ungarn. Organisationsstrukturen und Funktionsverständnis. Berlin: Berliner Debatte, 2003. - 211 S. ISBN 3-931703-86-X

\section{Mochtarova, Monika}

Erfolgreiche Geschäfte im östlichen Mitteleuropa. Polen, Tschechien, Ungarn. Berlin u.a.: Springer, 2000. - XVII, 193 S. ISBN 3-540-67211-7 


\section{Oesterwinter, Petra}

Die steueroptimale Direktinvestition in Ungarn unter besonderer Berücksichtigung von Anlaufverlusten. Lohmar; Köln: J. Eul, 2001. - XXIX, 365 S. (Steuer, Wirtschaft und Recht; 200) ISBN 3-89012-881-5

\section{Ohly, Claudia}

Das Steuersystem im ungarischen Transformationsprozess. Ein Beitrag zur Transformationstheorie. Frankfurt a. M.; Berlin; Bern; Bruxelles; New York; Oxford; Wien: Peter Lang Verlag, 2004. - XVI, 233 S. (Schriften zur internationalen Entwicklungs- und Umweltforschung; 11) ISBN 3-631-53053-6

\section{Olhausen, Manuela}

Politische Kommunikation im Wandel. Die deutschsprachige Presse des (ehemaligen) Ostblocks zwischen 1980 und 2000. Eine Inhaltsanalyse der Zeitungen "Neve Zeitung", Ungarn - "Prager Volkszeitung" Tschechoslowakei/Tschechien - „Neuer Weg" /"Allgemeine Deutsche Zeitung für Rumänien", Rumänien - "Neues Leben“, Sowjetunion/Russland in den Jahren 1980, 1989, 1990 und 2000. Hamburg: J. Kovac, 2005. - 632 S. (Schriftenreihe Communicatio; 7) ISBN 3-8300-1934-3

\section{Palmer, Christoph E. (Hrsg.)}

Europa wächst zusammen. Ungarns Beitrag. Stuttgarter Reden zu Europa mit Ferenc Mádl, Präsident der Republik Ungarn, am 5. Mai 2004 in Stuttgart. Stuttgart: Staatsministerium Baden-Württemberg, 2004. - 36 S. (Europaschriften des Staatsministeriums BadenWürttemberg) ISBN 3-9801995-4-1

\section{Pieper, Karin}

Regionalpolitik in Ungarn und Polen. Zwei Staaten im EU-Beitrittsprozess. Wiesbaden: Verlag für Sozialwissenschaften, 2005. - 320 S. (Forschungen zur europäischen Integration; 16) ISBN 3-531-14575-4

\section{Roth, Hans Karl}

Unternehmensgründung in Ungarn. Rechtsformen, Unternehmensstevern, Doppelbesteuerungsabkommen, Rechnungslegung, Immobilienerwerb. Wien: LexisNexis ARD Orac, 2004. - XIV, 114 S. (Orac Wirtschaftspraxis) ISBN 3-7007-3045-4

\section{Schirm, Magda (Hrsg.)}

Die neuen Gesichter Europas. Tschechien, Polen und Ungarn. Frankfurt a. M.: Verlag für Akademische Schriften, 2002. - 83 S. (Politik in sozialer und ökologischer Verantwortung) ISBN 3-88864-360-0 


\section{Schreiber, Elfi; Wippler, Regina}

Geschäftspartner Ungarn. Köln: Bundesagentur (bfai), 2000. - 178 S. ISBN 3-93407737-4

\section{Thelen, Tatjana}

Privatisierung und soziale Ungleichheit in der osteuropäischen Landwirtschaft. Zwei Fallstudien aus Ungarn und Rumänien. Frankfurt a. M.; New York: Campus-Verlag, 2003. 303 S. (Campus: Forschung; 865) ISBN 3-593-37346-7

\section{Velladics, Katalin}

Generationenvertrag und demographischer Wandel. Konsequenzen des aktiven Alterns für den Arbeitsmarkt am Beispiel Deutschlands und Ungarns. Mit einem Geleitwort von Patrick M. Liedke. Wiesbaden: Deutscher Universitäts-Verlag, 2004. - XIV, 176 S. ISBN 38244-0794-9

\section{Veser, Reinhard}

Die Neuen in der EU. Wien: Holzhausen Verlag, 2004 - 261 S. ISBN 3-85493-084-4

\section{Zarthe, Sascha}

Die militärischen Führungsphilosophien, Führungskonzeptionen und Führungskulturen Ungarns und Deutschlands im Vergleich. [Elektronische Ressource]. URL http://ub.unibwmuenchen.de/dissertationen/ediss/zarthe-sascha/inhat.pdf 


\section{Zeitschriften}

Berliner Beiträge zur Hungarologie. Schriftenreihe des Seminars für Hungarologie an der Humboldt-Universität zu Berlin. Herausgegeben von Ernő Kulcsár-Szabó u.a. Berlin; Budapest. HU ISSN 0238-2156

Bd. 12 (2001)

Bd. $13(2002 / 2003)$

Bd. 14 (2004)

Miteinander. Jahrbuch des Ungarischen Kulturinstituts Stuttgart. ISSN 1611-5600

Bd. 1 (2003): Eine Auswahl aus dem Programm des Ungarischen Kulturinstituts.

Bd. 2 (2004): Siehe II. Sachliteratur: Fassel, Horst.

Ungarn-Jahrbuch. Zeitschrift für interdisziplinäre Hungarologie. Herausgegeben von Gabriel Adriányi, Horst Glassl, Ekkehard Völkl. München: Ungarisches Institut. ISSN $0082-$ $755 \mathrm{X}$

Bd. $25(2000 / 2001)$ ISBN 3-929906-57-0

Bd. 26 (2002/2003) ISBN 3-929906-60-0

Bd. 27 (2004) ISBN 3-929906-61-9 



\section{KUnSt}




\section{Bildende Kunst, Fotografie, Film}

Időhíd / Zeitbrücke. Ungarische Kunst des 20. Jahrhunderts aus der Sammlung der Hauptstädtischen Gemäldegalerie Budapest. [Anlässlich der Ausstellung "Időhíd - Zeitbrücke. Ungarische Kunst des 20. Jahrhunderts. Aus der Sammlung der Hauptstädtischen Gemäldegalerie Budapest" im Rahmen der 49. Festspiele Europäische Wochen Passau im Museum Moderner Kunst - Stiftung Wörlen Passau vom 23. Juni bis 12. August 2001]. Passau: Museum Moderner Kunst - Stiftung Wörlen, 2001. - 202 S. ISBN 3-928844-34-2

\section{Bajkay, Éva (Hrsg.)}

Mattis-Teutsch und Der Blaue Reiter. [6. Juli-7. Oktober 2001]. München: Haus der Kunst, 2001. - $406 \mathrm{~S}$.

\section{Bajkay, Éva; Bakos, Katalin (Hrsg.)}

Modernizmusok. Európai grafika 1900-1930. Modernismen. Staatsgalerie Stuttgart, Graphische Sammlung, 16. Oktober 2004-23. Januar 2005. Stuttgart: Staatsgalerie; Budapest: Magyar Nemzeti Galéria, 2004. - 335 S.

\section{Bartl, Josef}

Zeichnungen. Mit einer Einführung von Eugen Christ. Budapest: VudAK, 2003. - 28 S. (VudAK-Bücher, Reihe Kunst; 2) ISBN 963-206-174-8

\section{Bereczky, Lóránd; Kocsis, András (Hrsg.)}

Mednyánszky. Ausstellung in der Ungarischen Nationalgalerie, 14. Oktober 2003-8. Februar 2004. [Aus dem Ungarischen übersetzt von Nóra Bessenyei]. Budapest: Kossuth, 2003. - 414 S. (Veröffentlichungen der Ungarischen Nationalgalerie; 2003, 2) ISBN 963-7432-88-4

\section{Biedermann, Gottfried}

Kunst-Landschaft Ungarn. [Würzburg]: Flechsig, 2003. - 218 S. ISBN 3-88189-475-6

\section{Birkás, Ákos}

In diesem Moment. [Ausstellung Ákos Birkás - In diesem Moment, Kunstverein Rosenheim, 18.06.-31.07.2005]. [Autoren: u.a. Endre Kukorelly]. Rosenheim: Kunstverein, 2005. 62 S. ISBN 3-9809544-6-3 


\section{Brunner, Michael (Hrsg.)}

Schätze aus Ungarn. Der Krönungsmantel und Kunstsammlung der Erzabtei Pannonhalma. Katalog des Städtischen Museums Engen + Galerie vom 20. September bis 23. November 2003. Engen: Hegau, 2003. - 190 S. (Begleithefte zur Ausstellung im Städtischen Museum Engen + Galerie) ISBN 3-9807457-8-3

\section{Direktor des Ungarischen Fotomuseums (Hrsg.)}

Photographen - made in Hungary. Die gegangen sind und die blieben ... [Zur Ausstellung Photographen Made in Hungary. Die gegangen sind und die blieben ... des Ungarischen Fotomuseums im Auswärtigen Am in Berlin vom 31. Mai bis 15. Juni 2001]. Kecskemét: Ungarisches Fotomuseum, 2001. - [44] S.

\section{Farbaky, Péter; Serfőzö, Szabolcs (Hrsg.)}

Ungarn in Mariazell - Mariazell in Ungarn. Geschichte und Erinnerung. Ausstellung des Historischen Museums der Stadt Budapest im Museum Kiscell, 28. Mai-12. September 2004. Budapest: Historisches Museum, 2004. - 556 S. ISBN 963-9340-38-3

\section{Filmmuseum Berlin; Deutsche Kinemathek (Hrsg.)}

Fluchtpunkt Ungarn. München: Edition Text \& Kritik, 2001. - 59 S. (FilmExil; 13) ISBN 388377-662-9

\section{Földényi, László F.}

Das Schweißtuch der Veronika. Museumsspaziergänge. Aus dem Ungarischen von Hans Skirecki. Frankfurt a. M.: Suhrkamp Verlag, 2001. - 204 S. (es; 22200) ISBN 3-51812220-7

\section{Grabner, Sabine; Markojá, Csilla (Hrsg.)}

László Mednyánszky. 1852-1919. Eine Ausstellung der Österreichischen Galerie Belvedere, Wien, 13. Oktober 2004-9. Jänner 2005. Wien: Österreichische Galerie Belvedere, 2004. - 121 S. (Wechselausstellung der Österreichischen Galerie Belvedere, Wien; 271) ISBN 3-901508-23-6

\section{Gundlach, F. C. (Hrsg.)}

Martin Munkácsi. Texte und Recherchen von Klaus Honnef und Enno Kaufhold. Göttingen: Steidl, 2005. - 415 S. ISBN 3-86521-099-6

\section{Heller, István}

Ungarische und siebenbürgische Goldschmiedearbeiten. Vom Ende des 16. Jahrhunderts bis zum Ende des 19. Jahrhunderts. München: Hirmer, 2000. - 312 S. ISBN 3-7774$8730-9$ 


\section{Honisch, Dieter (Hrsg.)}

Situation Ungarn. Kunst - vor und nach der Wende. [Anlässlich der Ausstellung Situation Ungarn, Kunst - vor und nach der Wende, 26. Oktober 2002-26. Januar 2003, MaxLiebermann-Haus am Brandenburger Tor, Stiftung Brandenburger Tor der Bankgesellschaft Berlin]. Berlin: G-und-H-Verlag, 2002. - 95 S. ISBN 3-931768-65-1

\section{Jurecskó, László (Hrsg.)}

Seelenblumen. János Mattis Teutsch, 1884 - 1960. Ausstellungsreihe; Ungarisches Kulturinstitut Collegium Hungaricum, Wien, 10.-30. Oktober 2002; Botschaft der Republik Ungarn, Berlin, 11. November 2002 - 10. Januar 2002; Kulturinstitut der Republik Ungarn, Stuttgart, 22. Januar-7. März 2003. Budapest; Miskolc: MissionArt Galerie, 2002. 65 S. ISBN 963-204-353-7

Mattis Teutsch und die Graphik der ungarischen Avantgarde. Budapest, Der Sturm, Bauhaus. Eine Ausstellung der MissionArt Galerie; Collegium Hungaricum, Berlin, 11. November 2002 - 15. Januar 2003. Budapest; Miskolc: MissionArt Galerie; Berlin: Collegium Hungaricum, 2002. - 72 S. ISBN 963-807-419-1

\section{Kertész, André}

André Kertész / Noel Bourcier. Berlin: Phaidon Verlag, 2001. - 125 S. ISBN 0-71489182-7

Kultur- und Sportamt Stadt Bietigheim-Bissingen; Städtische Galerie (Hrsg.) Der neue Adam und die neue Eva. Kunst der ungarischen Moderne aus der Ungarischen Nationalgalerie Budapest und dem Janus-Pannonius-Museum Pécs. [Ausstellung in der Städtischen Galerie Bietigheim-Bissingen vom 22. Januar bis zum 10. April 2005 und im KunstMuseum Ahlen vom 1. Mai bis zum 17. Juli 2005.] Heidelberg: Edition Braus, 2005. 208 S. 3-89904-145-3

\section{Kurucz, Gyula (Hrsg.)}

Ungarische Malerei in Baden-Württembergischen Privatsammlungen. [Anlässlich der Ausstellungsreihe "Ungarische Malerei in Baden-Württembergischen Privatsammlungen 1.-3." im Kulturinstitut der Republik Ungarn, Stuttgart, Oktober 2005-März 2006.

1. Die Sammlung Gracza. Ausstellung im Kulturinstitut der Republik Ungarn, Stuttgart, 23. September bis 28. Oktober 2005. Stuttgart: Kulturinstitut der Republik Ungarn, 2005. - 47 S. ISBN 963-218-933-7 


\section{Lindner, Gerd (Hrsg.)}

Tibor Csernus - zwischen Mythos und Realität. [Aus Anlass der Ausstellung „Tibor Csernus - Zwischen Mythos und Realität" vom 29. Januar 2005 bis zum 22. Mai 2005 im Panorama-Museum Bad Frankenhausen]. Bad Frankenhausen: Panorama-Museum, 2005. 111 S. ISBN 3-938049-01-4

\section{Lörincz, Zoltán}

„„... Die Bilder sind von uns genehmigt ..." Die Stellung der ungarischen Reformation zur Kunst und zur Architektur. Stadtschlaining: Concentrum, [2002]. - 201 S. ISBN 3-9501665$0-5$

\section{Masát, András (Hrsg.)}

Herzlichen Glückwunsch! Gratulálunk! Happy birthday to You ... Marta Eggerth wird 90. [Katalog der Ausstellung zu Ehren Marta Eggerths anläßlich ihres 90. Geburtstages im Collegium Hungaricum Berlin, 17. April bis 10. Mai 2002]. Leipzig: Edition Kirchhof und Franke, 2002. - 19 S. ISBN 3-933816-16-5

Kolonie der Träume. Nagybánya. [14. Februar bis 14. März 2002 im Gebäude der Botschaft der Republik Ungarn, Berlin]. Berlin: Collegium Hungaricum Berlin, 2002. - 95 S. ISBN 963-00-9481-9

\section{Matzon, Ákos}

Net. Budapest: VudAK, 2003. - [142] S. (VudAK-Bücher, Reihe Kunst; 4) ISBN 9638333-09-X

\section{Mészáros, Julia; Nagler, Gabriela; Patka, Erika; Straikammer, Roswitha (Hrsg.)}

Herzensschrei. Das Kind im Blick der Künste. Österreich und Ungarn 1900-2005. Wien: Universität für Angewandte Kunst Wien, 2005. - 76 S. ISBN 3-85211-121-8

\section{Nádas, Péter; Reuter, Jule (Hrsg.)}

Seelenverwandt. Ungarische Fotografen 1914-2003. [Martin-Gropius-Bau Berlin, 10. Juni bis 29. August 2005; eine Ausstellung des Fotomuseums Den Haag]. Berlin: Nicolaische Verlagsbuchhandlung, 2005. - 79 S. ISBN 3-89479-265-5

\section{Nagy, Katalin S.}

Der Holocaust in der bildenden Kunst in Ungarn zwischen 1938 und 1945. Collegium Hungaricum, Berlin; 10. Mai-3. Juli 2005. Berlin: Collegium Hungaricum Berlin, 2005. $31 \mathrm{~S}$. 


\section{Passuth, Krisztina}

Treffpunkte der Avantgarden. Ostmitteleuropa 1907-1930. Budapest: Balassi Kiadó; Dresden: Verlag der Kunst, 2003. - 337 S. ISBN 3-364-00605-9

\section{Pataky, Zita Ágota}

"Nympha ad amoenum fontem dormiens" Ekphrasis oder Herrscherallegorese? Studien zu einem Nymphenbrunnen sowie zur Antikerezeption und zur politischen Ikonographie am Hof des ungarischen Königs Matthias Corvinus. Stuttgart: Ibidem-Verlag, 2005. 622 S. ISBN 3-89821-446-X

\section{Rochard, Patricia (Hrsg.)}

Csárdás im Quadrat. Ungarische Avantgarde 1919- 1930 und traditionelle Bavernkultur. Mainz: H. Schmidt, 1995. - 192 S. ISBN 3-87439-362-3

\section{Rose Ausländer-Stiftung (Hrsg.)}

Die Malerin Rózsa Gottlieb. Die Schönheit der Linie, das Wunder der Farben. [Berlin]: AphorismA-Verlag, 2004. - 80 S. ISBN 3-86575-302-7

\section{Rüb, Matthias}

Die Junggesellen. Die letzten ungarischen Pusztabauern. Fotos von János Stekovics. Text Matthias Rüb. Halle an der Saale: János Stekovics Verlag, 1999. - 126 S. ISBN 3-92933097-0

\section{Trummer, Norbert; Hell, Bodo}

Budapest, Dob Utca. Zeichnungen von Norbert Trummer. Texte von Bodo Hell und einem Nachwort von Zsuzsanna Gahse. Innsbruck: Haymon, 1999. - 89 S. ISBN 3-85218308-1

\section{Wagner, János}

Arbeiten 1996-2002. Mit einer Einführung von Eugen Christ. Budapest: VudAK, 2003. 36 S. (VudAK-Bücher, Reihe Kunst; 3) ISBN 963-206-283-3 


\section{Architektur}

\section{Franke, Jan-Gunnar; Méhes, Márton (Hrsg.)}

Friedrich August Stüler - Das Akademiegebäude in Budapest. [Katalog zur Ausstellung „Baukunst - Mitteleuropäisch" des Collegium Hungaricum Berlin, Januar/Februar 2002 in der Botschaft der Republik Ungarn, Berlin]. Leipzig: Edition Kirchhof und Franke, 2001. - 24 S. ISBN 3-933816-12-2

Kapfinger, Otto (Hrsg.)

Neue Architektur in Burgenland und Westungarn. Salzburg: Anton Pustet, 2004. - [213] S. ISBN 3-7025-0495-8

\section{Markovecz, Imre}

Bewegte Form. Der Architekt Imre Markovecz. [Übersetzung aus dem Ungarischen von Péter Kardos]. Stuttgart: Urachhaus, 2002. - 323 S. ISBN 3-8251-7349-6

Sinkó, Katalin (Hrsg.)

Das Sándor-Palais in Schrift und Bild. [Aus dem Ungarischen übersetzt von Albrecht Friedrich]. Budapest: Akadémiai Kiadó, 2003. - 137 S. ISBN 963-05-8090-X 



\section{Ü BERSETZERREGISTER}

(Belletristik) 


\begin{tabular}{ll}
\hline Alkalay, Edmund $\rightarrow$ & Molnár, Ferenc \\
\hline Ban, Margit $\rightarrow$ & Márai, Sándor \\
\hline Berger, Erich $\rightarrow$ & Kertész, Imre \\
\hline Brunner-Sobanski, Elisabeth $\rightarrow$ & Várkonyi, Zsuzsa F. \\
\hline Budunsch, Wolfgang $\rightarrow$ & Ady, Endre \\
\hline Buschmann, Jörg $\rightarrow$ & Kertész, Imre; Lakatos, Menyhért; Méhes, Károly; \\
\hline Deréky, Géza $\rightarrow$ & Sziil, Ferenc; Tolnai, Ottó \\
\hline Deréky, Pál $\rightarrow$ & Görgey, Gábor \\
\hline Detrich, Julius Alexander $\rightarrow$ & Kertész, Imre; Méhes, György; Tolnai, Ottó \\
\hline Doma, Ákos $\rightarrow$ & Garaczi, László \\
\hline Droste, Wilhelm $\rightarrow$ & Ady, Endre \\
\hline Eisterer, Heinrich $\rightarrow$ & Földényi, László F.; Nádas, Péter \\
\hline Feidel, Gotffried $\rightarrow$ & Hamvas, Béla; Schein, Gábor \\
\hline Gühmann, Franz $\rightarrow$ & Darvasi, László; Márai, Sándor; Nádas, Péter \\
\hline Gahser, Ruth $\rightarrow$ & Szepes, Maria \\
\hline Kalász, Márton
\end{tabular}




\begin{tabular}{|c|c|}
\hline Harmat, Georg $\rightarrow$ & Heltai, Jenő \\
\hline Jahn Brandenstein, Maria $\rightarrow$ & Györffy, László \\
\hline Jeszenkovits, Terézia $\rightarrow$ & Gárdonyi, Géza \\
\hline Kárpáti, Paul $\rightarrow$ & $\begin{array}{l}\text { Bitók, László; Illyés, Gyula; Kalász, Márton; } \\
\text { Kányádi, Sándor; Márai, Sándor; Nagy, Gáspár; } \\
\text { Vörösmárty, Mihály }\end{array}$ \\
\hline Koenen, Krisztina $\rightarrow$ & Kertész, Imre \\
\hline Kornitzer, László $\rightarrow$ & Kertész, Imre; Nádas, Péter \\
\hline Kunze, Christina $\rightarrow$ & Bozai, Ágota \\
\hline Langanke, Martin $\rightarrow$ & Horváth, Ottó \\
\hline Lenard, Alexander $\rightarrow$ & Szerb, Antal \\
\hline Lindt, Anna von $\rightarrow$ & Howard P. [d.i. Rejtő, Jenő] \\
\hline Máté, Angelika $\rightarrow$ & Zsolt, Béla \\
\hline Máté, Péter $\rightarrow$ & Eörsi, István \\
\hline Máté, Angelika und Péter $\rightarrow$ & Kertész, Imre \\
\hline Mayer, Gregor $\rightarrow$ & Eörsi, István \\
\hline Mora, Terézia $\rightarrow$ & $\begin{array}{l}\text { Darvasi, László; Esterházy, Péter; Örkény, István; } \\
\text { Parti Nagy, Lajos; Zilahy, Péter }\end{array}$ \\
\hline Muth, Daniel [d.i. Báthori, Csaba] $\rightarrow$ & Balla, Zsófia; József, Attila \\
\hline Nagel, Ivan $\rightarrow$ & Déry, Tibor \\
\hline Neumann-Veith, Eta $\rightarrow$ & Zilahy, Lajos \\
\hline
\end{tabular}


Neutsch, Andreas $\rightarrow$

Paetzke, Hans-Henning $\rightarrow$
Tóthfalusi, István

Esterházy, Péter; Konrád, György; Mándy, Iván; Márton, László

Eörsi, István

Kertész, Imre; Márai, Sándor

Balázs, Béla

Kertész, Imre; Nádas, Péter

Bartis, Attila; Darvasi, László; Kertész, Imre; Márton, László; Zilahy, Péter

Petőfi, Sándor

Rübberdt, Irene $\rightarrow \quad$ Domokos, Johanna; Kertész, Imre

Saternus, Arthur $\rightarrow$

Márai, Sándor

Schade-Engl, Henriette $\rightarrow$

Jókai, Mór

Scharf, Erika $\rightarrow$

Márton, Franz

Schiff, Julia und Robert $\rightarrow$

Kalász, Márton

Schlosser, Christine $\rightarrow$

Domokos, Johanna

Schwamm, Kristin $\rightarrow$

Kertész, Imre

Seidler, Andrea $\rightarrow$

Garaczi, László; Sziii, Ferenc; Zilahy, Lajos

Simányi, Tibor $\rightarrow$

Márai, Sándor

Skirecki, Hans $\rightarrow$

Eörsi, István; Esterházy, Péter; Földényi, László F.; Gergely, Ágnes; Krúdy, Gyula; Márai, Sándor; Pap, Károly 
Stipsicz-Gariboldi, Renée von $\rightarrow$

Szent-lványi, Ita $\rightarrow$

Toth, J. P. / A. Luther $\rightarrow$

Viragh, Christina $\rightarrow$
Márai, Sándor

Székely, János

Harsányi, Zsolt

Kertész, Imre; Kosztolányi, Dezső; Krasznahorkai, László; Márai, Sándor; Szerb, Antal

Gárdonyi, Géza

Zeltner, Ernö $\rightarrow$
Kertész, Imre; Márai, Sándor; Rakovszky, Zsuzsa; Vámos, Miklós 


\section{Göttinger Bibliotheksschriften}

(lieferbare Titel, Stand: 1. 11. 2006)

1. Edith Stein. Studentin in Göttingen 1913-1916. Ausstellung zum 100. 4,- $€$ Geburtstag 7.10.-28.10.1991. 1991. 118 S.

2. Der Brocken und sein Alpengarten. Erinnerungen - Dokumentationen. 4,- $€$ Ausstellung vom 17.3.-5.6.1993. 1993. $81 \mathrm{~S}$.

3. Übersicht über die Systematik des Bandrealkataloges der Niedersäch$5,-€$ sischen Staats- und Universitätsbliothek Göttingen. Bearb.: G.-J. Bötte u. D. Sickmüller. 1993. XIII, 75, $126 \mathrm{~S}$.

4. Neues Heimatland Brasilien. Texte und Bilder zur kulturellen Entwicklung der deutsch-brasilianischen Bevölkerung in Südbrasilien. Begleitband zur Ausstellung vom 10.1.-19.2.1994 / Sandra Messele-Wieser, Lothar Wieser. 1994. IV, 84 S.

5. Möglichkeiten der Beschaffung und Bereitstellung digitaler Karten im Sondersammelgebiet. DFG-Projektstudie. Bearb. von Christiane Beckert. 2002. 142 S.

6. Kröger, Detlef: European and international Copyright protection. Microcopies and databases. 1995. 283 S.

7. Bestandserhalt durch Konversion: Microverfilmung und alternative Tech- 10,- $€$ nologien. Beiträge zu drei Fachtagungen des EU-Projekts MICROLIB. 1995. 208 S.

10. Sibirien Finnland Ungarn : Finnisch-ugrische Sprachen und Völker in der Tradition eines Göttinger Sondersammelgebiets. Ausstellung in der Paulinerkirche vom 28.2.-9.4.1998. 344 S.

13. "Göthe ist schon mehrere Tage hier, warum weiß Gott und Göthe": 14,- $€$ Vorträge zur Ausstellung „Der gute Kopf leuchtet überall hervor” Goethe, Göttingen und die Wissenschaft. 2000. VI, 295 S.

14. Towards consensus on the electronic use of publications in libraries: $7,-€$ strategy issues and recommendations / Thomas Dreier. 2001. 120 S.

16. Zehn Jahre Pica in Niedersachsen und Deutschland. Skizzen eines Erfolges. $5,-€$ 2001. $181 \mathrm{~S}$.

17. "Wohne immer in meinem Herzen und in den Herzen meiner Freunde 10,- $€$ allesbelebende Liebe!" Friedrich Leopold Graf zu Stolberg (1750-1819). Aus der literarisch-historischen Sammlung des Grafen Franz zu StolbergStolberg, 1210 - 1750 - 2001 / Bearb. von Paul Kahl. 2001. 143 S. 
18. Johann Heinrich Voß. 1751-1826. Idylle, Polemik, Wohllaut. 2001. 298 S. 15,-€

19. Weltbild - Kartenbild. Geographie und Kartographie in der frühen Neuzeit $10,-€$ / Bearb. von Mechthild Schüler. 2. Aufl. 2002. 94 S.

20. LIBER - Ligue des Bibliothèques Européennes de Recherche. Architecture 35,- $€$ Group Seminar. Leipzig, March 19-March 23, 2002. The Effective Library. Vision, Planning Process and Evaluation in the Digital Age. Documentation of new library buildings in Europe. 2002. 319 p.

21. Das Göttinger Nobelpreiswunder - 100 Jahre Nobelpreis. 2. Aufl. 2002. 22,-€ $377 \mathrm{~S}$.

22. 300 Jahre St. Petersburg - Russland und die "Göttingische Seele". 2. Aufl. 14,- $€$ 2004. $502 \mathrm{~S}$.

23. Das Göttinger Nobelpreiswunder - 100 Jahre Nobelpreis. Vortragsband. 11,- $€$ 2004. $194 \mathrm{~S}$.

24. Daniela Grebler, Kornelia Priesel-Agidigbi, Dirk Steinert: In Sachen AACR2. Eine Bibliographie zur Second edition der Anglo-American cataloguing rules mit originalsprachigen und übersetzten Ausgaben sowie englischund deutschsprachiger Sekundärliteratur 1978-2002. 2004. V, 160 S.

25. LIBER - Ligue des Bibliothèques Européennes de Recherche. Architecture Group Seminar. Bozen/Bolzano, March 17-March 19, 2004. The Renaissance of the Library - adaptable library buildings. Documentation of new library buildings in Europe. 2004. 367 p.

26. Edward S. Curtis: The North American Indian. Die Indianer Nordamerikas. Ausstellung in der Niedersächsischen Staats- und Universitätsbibliothek Göttingen, 29.2.-18.4.2004 / Mit einer Einf. von Hans Christian Adam. 2004. 72 S.

27. Dieter Cherubim, Ariane Walsdorf: Sprachkritik als Aufklärung - Die Deutsche Gesellschaft in Göttingen im 18. Jahrhundert. 2. Aufl. 2005. 237 S.

28. Anne Ørbæk Jensen, Claus Røllum-Larsen, Inger Sørensen: Wahlverwandtschaften - Zwei Jahrhunderte musikalischer Wechselwirkungen zwischen Dänemark und Deutschland. 2004. 115 S.

29. Nützliches Vergnügen. Kinder- und Jugendbücher der Aufklärungszeit aus dem Bestand der Niedersächsischen Staats- und Universitätsbibliothek Göttingen und der Vordemann-Sammlung. 2004. 259 S.

30. "Wie der Blitz einschlägt, hat sich das Räthsel gelöst" - Carl Friedrich Gauß 12,- € in Göttingen. 2005. 252 S. 
31. „Eine Welt allein ist nicht genug" - Großbritannien, Hannover und 16,- $€$ Göttingen 1714-1837. 2005. 450 S.

32. Kerstin Thieler: „[...] des Tragens eines deutschen akademischen Grades $8,-€$ unwürdig." Die Entziehung von Doktortiteln an der Georg-AugustUniversität Göttingen im „Dritten Reich". 2. Aufl. 2006. 104 S.

33. Die spanische Aufklärung in Deutschland. Eine Ausstellung aus den Beständen der Niedersächsischen Staats- und Universitätsbibliothek Göttingen. 2005. 114 S.

34. LIBER - Ligue des Bibliothèques Européennes de Recherche. Architecture $36,-€$ Group Seminar. Utrecht, The Netherlands, March 22 - March 24, 2006 with a pre-seminar tour in Belgium and the south of The Netherlands, March 20/21, 2006. Changing Needs, Changing Libraries. Documentation of new library buildings in Europe. 2006. 327 p.

35. Göttinger Kostbarkeiten - Handschriften, Drucke und Einbände aus zehn 29,80€ Jahrhunderten. 2006. 286 S.

\section{CD-ROM der SUB Göttingen}

(lieferbare Titel, Stand: 1. 11. 2006)

Die ganze Welt ist aus Papier. Graphiken und Objekte zu allen Gelegenheiten 1800-1930.

"Der gute Kopf leuchtet überall hervor" - Goethe, Göttingen und die Wissenschaft.

Gutenberg digital. Göttinger Gutenberg-Bibel, Musterbuch und Helmaspergersches Notariatsinstrument.

Weltbild - Kartenbild. Geographie und Kartographie in der frühen Neuzeit.

Das Göttinger Nobelpreiswunder - 100 Jahre Nobelpreis.

300 Jahre St. Petersburg - Russland und die "Göttingische Seele".

$18,-€$

$15,-€$

$54,-€$

$20,-€$

$18,-€$

$14,-€$

The North American Indian - Fotografien von Edward S. Curtis.

$6,-€$

Nützliches Vergnügen. Kinder- und Jugendbücher der Aufklärungszeit aus

$12,-€$ dem Bestand der Niedersächsischen Staats- und Universitätsbibliothek Göttingen und der Vordemann-Sammlung.

„Wie der Blitz einschlägt, hat sich das Räthsel gelöst" - Carl Friedrich Gauß

$12,-€$ in Göttingen.

Göttinger Kostbarkeiten - Handschriften, Drucke und Einbände aus zehn

$9,80 €$ Jahrhunderten. 